\title{
Dependence of Eemian Greenland temperature reconstructions on the ice sheet topography
}

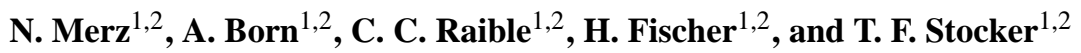 \\ ${ }^{1}$ Climate and Environmental Physics, University of Bern, Bern, Switzerland \\ ${ }^{2}$ Oeschger Centre for Climate Change Research, University of Bern, Bern, Switzerland \\ Correspondence to: N. Merz (merz@ climate.unibe.ch)
}

Received: 27 November 2013 - Published in Clim. Past Discuss.: 23 December 2013

Revised: 7 April 2014 - Accepted: 19 May 2014 - Published: 25 June 2014

\begin{abstract}
The influence of a reduced Greenland Ice Sheet (GrIS) on Greenland's surface climate during the Eemian interglacial is studied using a set of simulations with different GrIS realizations performed with a comprehensive climate model. We find a distinct impact of changes in the GrIS topography on Greenland's surface air temperatures (SAT) even when correcting for changes in surface elevation, which influences SAT through the lapse rate effect. The resulting lapse-rate-corrected SAT anomalies are thermodynamically driven by changes in the local surface energy balance rather than dynamically caused through anomalous advection of warm/cold air masses. The large-scale circulation is indeed very stable among all sensitivity experiments and the Northern Hemisphere (NH) flow pattern does not depend on Greenland's topography in the Eemian. In contrast, Greenland's surface energy balance is clearly influenced by changes in the GrIS topography and this impact is seasonally diverse. In winter, the variable reacting strongest to changes in the topography is the sensible heat flux (SHF). The reason is its dependence on surface winds, which themselves are controlled to a large extent by the shape of the GrIS. Hence, regions where a receding GrIS causes higher surface wind velocities also experience anomalous warming through SHF. Vice-versa, regions that become flat and ice-free are characterized by low wind speeds, low SHF, and anomalous low winter temperatures. In summer, we find surface warming induced by a decrease in surface albedo in deglaciated areas and regions which experience surface melting. The Eemian temperature records derived from Greenland proxies, thus, likely include a temperature signal arising from changes in the GrIS topography. For the Eemian ice found in the NEEM core, our model suggests that up to $3.1^{\circ} \mathrm{C}$ of the annual
\end{abstract}

mean Eemian warming can be attributed to these topographyrelated processes and hence is not necessarily linked to largescale climate variations.

\section{Introduction}

The Greenland Ice Sheet (GrIS) is a valuable archive of paleoclimate data, which can be accessed by drilling ice cores. Stable isotopes in the ice matrix $\left(\delta^{18} \mathrm{O}_{\text {ice }}, \delta \mathrm{D}_{\text {ice }}\right)$ and in the air enclosed $\left(\delta^{15} \mathrm{~N}_{\text {air }}\right)$ are used to reconstruct past temperatures (Jouzel et al., 2007; NEEM community members, 2013; Kindler et al., 2014) over the age range of the ice core, i.e., up to 130 thousand years for the deep Greenland ice cores. Thus, Greenland temperature records from ice cores are able to cover the present interglacial (the Holocene), the last glacial, and in case of the NEEM core (NEEM community members, 2013) even the last interglacial period (the Eemian). In order to interpret reconstructed Greenland temperatures correctly and to distinguish between local and global signals a thorough knowledge of Greenland's climate is required. The complex topography with steep slopes along the ice margins and a relatively flat, high-elevation inland plateau causes a diverse local surface climate. The high altitude and the highly reflective ice surface in central Greenland ensure very cold and dry conditions throughout the year, whereas temperatures in coastal regions are more moderate and passing cyclones generate high precipitation that mainly falls orographically induced over the coastal slopes.

As Greenland's climate is closely tied to its ice sheet any change in the GrIS topography will also interact with the local climate. The last time in the past when the GrIS is known 
to have been significantly reduced was during the Eemian interglacial (ca. 130-116 ka). This interglacial was characterized by stronger summer insolation and warmer conditions in the high latitudes of both hemispheres compared to preindustrial (PI) conditions, whereas greenhouse gas (GHG) concentrations were on a comparable level. Nevertheless, the warming induced by the orbital forcing led to significant melting of the ice sheets. Coral reef data suggest that the sea level was likely $4-9 \mathrm{~m}$ higher than today (Overpeck et al., 2006; Kopp et al., 2009). This sea level rise needs considerable contributions from both the Greenland and the Antarctic Ice Sheet. Thus, a number of ice sheet modeling studies have investigated the response of the GrIS to Eemian climate conditions using different approaches (Cuffey and Marshall, 2000; Otto-Bliesner et al., 2006; Robinson et al., 2011; Born and Nisancioglu, 2012; Stone et al., 2013; Helsen et al., 2013). The results show that reconstructed contributions of the GrIS to the sea level high stand cover a wide range from almost none to over $5 \mathrm{~m}$ of sea level rise, which corresponds to a loss of up to $80 \%$ of the present-day GrIS volume.

Any substantial melting of the GrIS will change Greenland's topography and surface conditions. Consequently, a significantly reduced Eemian GrIS likely has an effect on climate. This response of the climate system to a change in the GrIS topography will be referred to as "sensitivity to GrIS topography" throughout this paper. The strongest sensitivity is expected on Greenland's local surface climate. However, due to its massive height (over $3200 \mathrm{~m}$ ) and extent (over $2600 \mathrm{~km}$ meridionally and $1000 \mathrm{~km}$ zonally) Greenland is also known to impact the atmospheric flow on both the synoptic and planetary scale (Kristjansson and McInnes, 1999; Petersen et al., 2004). Thus, substantial melting of the GrIS is expected to have an influence on the Northern Hemisphere (NH) atmospheric flow and, thus, might also impact downstream areas, such as Europe. Previous studies investigating the sensitivity to changes in the GrIS topography have mainly used present or pre-industrial climate conditions and idealized GrIS configurations. Thus, Greenland's topography was set to be flat (Petersen et al., 2004; Junge et al., 2005; Kristjansson et al., 2009), equal to bedrock (Toniazzo et al., 2004; Lunt et al., 2004), or multiplied by a scaling factor (Kristjansson and McInnes, 1999; Hakuba et al., 2012). Whereas most of these studies are based on atmospheric model simulations, Lunt et al. (2004) used a fully coupled model to investigate feedback mechanisms with other components of the climate system such as NH sea ice.

In this study, we analyze the impact of a reduced GrIS on the Eemian climate using the atmospheric (and land) component of a high-resolution climate model. In contrast to the approach with an idealized reduction of the GrIS, we implement GrIS masks as simulated for the Eemian climate in two recent ice sheet modeling efforts which are constrained by present and paleo-information (Robinson et al., 2011; Born and Nisancioglu, 2012). With the inclusion of these somewhat more realistic realizations of the GrIS, the simulations allow us to quantify the impact of a reduced GrIS on Greenland's Eemian climate. The results of this study, hence, will be a valuable addition to the state-of-art Eemian modeling studies (e.g., Bakker et al., 2013), which neglect the effect of a reduced GrIS. Furthermore, our study contributes to the interpretation of temperature records for the Eemian based on proxy data such as the NEEM record (NEEM community members, 2013).

In particular, the questions of to which extent the remarkable warming in the Eemian ice found at NEEM $\left(8 \pm 4^{\circ} \mathrm{C}\right.$ according to $\delta^{18} \mathrm{O}$, and $5^{\circ} \mathrm{C}$ according to $\delta^{15} \mathrm{~N}$ ) can be interpreted as a large-scale temperature signal or whether smallscale processes are important are investigated. In order to answer these questions, we study in detail the effect of a reduced GrIS on Greenland surface temperatures and the underlying processes. In contrast, the topography effect on Greenland's surface mass balance is beyond the scope of this paper and will be addressed elsewhere.

The manuscript is structured as follows: in Sect. 2 we describe the experimental setup and the implemented ice sheets. In Sects. 3-5 the response of the temperature, the atmospheric circulation, and the surface energy balance over Greenland to GrIS change are presented. Section 6 discusses the implications of the key processes, which lead to a different Eemian temperature signal at various Greenland ice core sites related to changes in the Greenland topographies. Finally, conclusions are presented in Sect. 7.

\section{Model setup and simulations}

We use the Community Climate System Model (version 4, CCSM4) developed at the National Center for Atmospheric Research (Gent et al., 2011). All simulations are performed with the CCSM4 atmosphere-land-only setup, also known as AMIP-type simulation. The model setup couples the Community Atmosphere Model version 4 (CAM4; Neale et al., 2010) with the Community Land Model version 4 (CLM4; Oleson et al., 2010). The Community Ice CodE version 4 (CICE4; Hunke and Lipscomb, 2008) is used in the thermodynamic-only mode so sea ice concentration fields are prescribed but surface fluxes are computed by taking into account snow depth, albedo, and surface temperature over the ice using one-dimensional thermodynamics. Over the oceans, monthly sea surface temperatures (SST) are prescribed as lower boundary conditions. The horizontal resolution of $0.9^{\circ} \mathrm{C} \times 1.25^{\circ} \mathrm{C}$ (equal to a grid cell size of $100 \mathrm{~km} \times 50 \mathrm{~km}$ resolution at $70^{\circ} \mathrm{N}$ ) in all components allows an analysis of regional climate features. The vertical resolution in the atmosphere is 26 layers.

As this study focuses on Greenland's surface climate, processes occurring within the atmospheric boundary layer and concerning the (partially) snow-covered land surface are of importance. For the former, the atmospheric model (CAM4) uses the non-local atmospheric boundary layer 
Table 1. List of model simulations and the forcing used in the experiments. Present-day levels are denoted as pd, pre-industrial levels as pi. The orbital parameters are calculated according to Berger (1978). SST and sea ice fields are outcomes of corresponding fully coupled CCSM3 simulations (see Sect. 2.1 for details). Solar forcing is expressed as total solar irradiance (TSI) and corresponds to the CCSM4 standard pre-industrial level. The set of implemented ice sheet topographies is shown in Figs. 2 and 3.

\begin{tabular}{llllllll}
\hline Simulation & $\begin{array}{l}\text { Orbital } \\
\text { parameters }\end{array}$ & SST/sea ice & $\begin{array}{l}\mathrm{CO}_{2} \\
(\mathrm{ppm})\end{array}$ & $\begin{array}{l}\mathrm{CH}_{4} \\
(\mathrm{ppb})\end{array}$ & $\begin{array}{l}\mathrm{N}_{2} \mathrm{O} \\
(\mathrm{ppb})\end{array}$ & $\begin{array}{l}\mathrm{TSI} \\
\left(\mathrm{W} \mathrm{m}^{-2}\right)\end{array}$ & Ice sheets \\
\hline PI & pd & $\mathrm{pi}$ & 280 & 760 & 270 & 1360.9 & $\mathrm{pd}$ \\
EEMpd & $125 \mathrm{ka}$ & $125 \mathrm{ka}$ & 272 & 622 & 259 & 1360.9 & $\mathrm{pd}$ \\
EEMr1 & $125 \mathrm{ka}$ & $125 \mathrm{ka}$ & 272 & 622 & 259 & 1360.9 & EEMr1 \\
EEMr2 & $125 \mathrm{ka}$ & $125 \mathrm{ka}$ & 272 & 622 & 259 & 1360.9 & EEMr2 \\
EEMr3 & $125 \mathrm{ka}$ & $125 \mathrm{ka}$ & 272 & 622 & 259 & 1360.9 & EEMr3 \\
EEMr4 & $125 \mathrm{ka}$ & $125 \mathrm{ka}$ & 272 & 622 & 259 & 1360.9 & EEMr4 \\
\hline
\end{tabular}

parameterization by Holtslag and Boville (1993), described in details by Neale et al. (2010). The land model (CLM4) accounts for changes in surface characteristics emerging from snow-related processes. The corresponding snow scheme (Oleson et al., 2010) incorporates various processes such as snow aging through dry snow metamorphism, liquid-waterinduced metamorphism, and refreezing of liquid water. The resulting changes in the ice effective grain size have important implications for the surface albedo (Oleson et al., 2010).

A general model validation of the CCSM4 atmosphereland-only setup is presented in Evans et al. (2013), denoted as CAM-FV simulation therein. An evaluation CAM4 is further provided in Neale et al. (2013). The fully coupled CCSM4 with $0.9^{\circ} \times 1.25^{\circ}$ horizontal resolution (called CESM therein) has been specifically validated against the regional model RACMO2 (Ettema et al., 2010) concerning its representation of Greenland's climate (Vizcaino et al., 2013). It is shown that CCSM4 reasonably simulates surface air temperatures (SAT) as well as the components of the surface energy balance over Greenland. As Vizcaino et al. (2013) mainly focused on summer heat fluxes, we repeated the model validation for the winter season also using RACMO2 (Ettema et al., 2010) as a reference. In doing so we could confirm that CCSM4 represents well the components of the Greenland climate system that are of importance for this study, namely SAT, surface winds, and the surface energy fluxes (not shown).

\subsection{Experiments}

A set of so-called time-slice simulations is performed where all external forcing factors are held constant throughout the simulations. A PI simulation with perpetual AD 1850 conditions is used as reference simulation for the paleosimulations since it describes the present climate without perturbation by human activities. This PI simulation has previously been used and described in Merz et al. (2013). Moreover, five Eemian (referred to as EEM) sensitivity simulations with perpetual $125 \mathrm{ka}$ conditions but different GrIS im- plementations are conducted: EEMpd with present-day GrIS, EEMr1 with a moderately retreated GrIS from Robinson et al. (2011), EEMr2 with a strongly retreated GrIS from Robinson et al. (2011), EEMr3 with the same GrIS mask as EEMr2 but without the South Dome, and EEMr4 with the simulated Eemian GrIS from Born and Nisancioglu (2012).

Eemian climate signals attributed to the orbital forcing are calculated as EEMpd-PI and are briefly described in Sect. 2.3. The EEMpd simulation is further used as reference simulation to compare with the four GrIS sensitivity simulations (EEMr1-EEMr4). More details of the different ice sheet configurations in the EEM experiments are provided in Sect. 2.4. A general overview of all simulations and the external forcing factors is also given in Table 1. Note that all simulations are conducted for 33 model years and that the analysis is based on the last 30 years of each simulation.

\subsection{Boundary conditions}

The implemented boundary conditions are as follows: Monthly-mean sea-surface temperature (SST) and sea ice fields used as time-varying lower boundary conditions are obtained from corresponding simulations with the fully coupled CCSM3. These simulations are conducted with the lowresolution CCSM3 (Yeager et al., 2006) model version. For the PI simulation we use output of a control AD 1850 simulation by Merkel et al. (2010) and for the Eemian simulations we take 33-year output at around $125 \mathrm{ka}$ from a transient (130-115 ka) orbitally accelerated Eemian simulation (CCSM3 run in Bakker et al., 2013). With this setup we account for the different states of the ocean and sea ice cover during the two climate periods. However, since the CCSM3 simulations are run in a low-resolution setup we partly inherit model biases from CCSM3, the most prominent being a too-excessive NH sea ice cover and a too-cold North Atlantic Ocean for present-day conditions. Since these biases apply to all simulations, they do not directly impact the anomalous fields shown in this study and are not expected to critically influence the results. The Eemian solar insolation is 
calculated with orbital parameters set to $125 \mathrm{ka}$ levels using Berger (1978). The greenhouse gas (GHG) concentrations are set according to the PMIP protocol and listed in Table 1.

\subsection{Orbital forcing response}

The EEMpd simulation with present-day GrIS is regarded as the baseline Eemian climate simulation. Compared to PI, EEMpd particularly differs with respect to the implemented orbital parameters and the surface boundary conditions, i.e., SST and sea ice cover. In contrast, GHG levels are comparable to PI (Table 1) and the other forcing parameters are unchanged. Hence the Eemian climate in EEMpd is dominated by the Milankovitch forcing, which includes a larger obliquity and summer solstice closer to perihelion for the Eemian compared to pre-industrial values. This results in stronger $\mathrm{NH}$ insolation during summer, particularly in the high latitudes. $\mathrm{NH}$ winter insolation is decreased so the NH Eemian climate exhibits an enhanced seasonal cycle similar but even more pronounced than during the midHolocene (Fischer and Jungclaus, 2010). The enhanced seasonality translates into respective surface air temperature (SAT) anomalies (see shading in Fig. 1). Consequently, the EEMpd-PI NH winter temperatures show a widespread cooling. Vice-versa, NH summer temperatures in the EEMpd simulation are clearly higher than in PI, particularly and continental regions. The distinct spatial variability in Eemian summer warming across the NH agrees with temperature reconstructions (CAPE Last Interglacial Project Members, 2006). Regarding Greenland, EEMpd simulates a rather uniform $2-4{ }^{\circ} \mathrm{C}$ summer warming compared to PI induced by the large increase in summer insolation. In contrast, due to its high latitudinal position, Greenland is hardly affected by the reduction in winter insolation so the EEMpd DJF temperatures are moderately colder but not significantly different from PI. Concerning the large-scale circulation, the EEMpd-PI orbital forcing leads to a weakening of the meridional pressure gradient during $\mathrm{NH}$ winters (see contours in Fig. 1), significantly slowing down the westerly flow towards Greenland. During summer, the extensive warming leads to a widespread decrease in sea level pressure (SLP) and the anomaly pattern over the North Atlantic shows rather an enhancement of the westerly flow towards Greenland. However, these circulation changes do not seem to be of importance for explaining the EEMpd-PI Greenland SAT differences and the flow anomalies evoked by the orbital forcing do not change Greenland's spatial temperature pattern. Note that the large-scale climate simulated in EEMpd overall matches very closely the Eemian CCSM3 simulation by Nikolova et al. (2013) and interested readers are referred to their paper for more details concerning the impact of the Eemian orbital forcing.

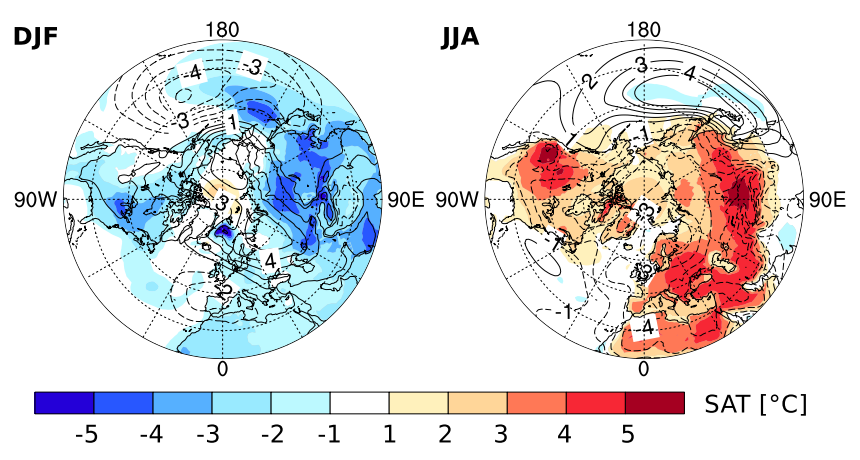

Figure 1. EEMpd-PI SAT $\left({ }^{\circ} \mathrm{C}\right.$ ) (shaded) over SLP (hPa) (contour lines with labels) for DJF and JJA. The contour interval is $1 \mathrm{hPa}$, negative values are dashed, and the zero line is not shown.

\subsection{Eemian Greenland ice sheets}

The Eemian sea level estimates by coral reefs provide no information about how much of the sea level rise can be attributed to melting of the GrIS. On Greenland itself, air content measurements from the ice cores of the summit region (GISP2, GRIP, NGRIP) indicate that the Eemian surface elevation were no more than a few hundred meters lower than present-day (Raynaud et al., 1997) as it is the case for the most recent Greenland ice core (NEEM, NEEM community members, 2013). In contrast, Eemian ice from the Camp Century (CC) and DYE3 ice cores indicates a substantial lowering of the surface elevation at these sites. The existence of Eemian ice of DYE3 (and the South Dome) was questioned by Alley et al. (2010) though recent results by Colville et al. (2011) and Willerslev et al. (2007) support the persistence of the South Dome throughout the last interglacial. However, due to scarcity of proxy archives close to the GrIS margins, there is very limited information about the actual Eemian GrIS topography. Thus, the actual shape and extent of the Eemian GrIS is not sufficiently known and can only be estimated through ice sheet modeling efforts leading to a remarkable variety of simulated Eemian GrIS masks. Cuffey and Marshall (2000) and Otto-Bliesner et al. (2006) found strong melting in southern Greenland whereas Robinson et al. (2011) simulate strong melting in western and northern Greenland. Again, Born and Nisancioglu (2012) found a strong retreat of northeastern GrIS. However, as the paleo-ice sheets are weakly constrained due to the limited amount of data available, it is difficult to judge which of the proposed Eemian GrIS is most likely. Hence, for this study we implement a set of different plausible GrIS ice sheet masks and test their influence on the local surface climate.

The positions of the ice sheet margins in the five different GrIS implemented in our Eemian experiments are shown in Fig. 2. Compared with the reference simulation with the present-day GrIS (EEMpd) all perturbed experiments (EEMr1-EEMr4) include a smaller ice sheet in terms 


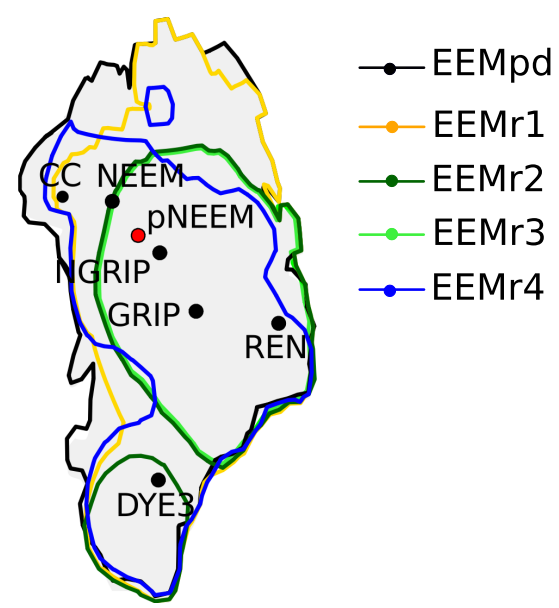

Figure 2. Greenland Ice Sheet margins in the Eemian sensitivity experiments illustrated as contour lines of $10 \%$ land ice coverage. The black dots indicate the locations of the ice core sites of Camp Century (CC), NEEM, NGRIP, GRIP, and DYE3. The red dot points at pNEEM, i.e., the supposed deposition site of Eemian ice found in the NEEM ice core according to NEEM community members (2013).

of area covered. In EEMr1 the GrIS has moderately retreated from the west in northwestern and central-western Greenland so that CC is newly located at the ice sheet margin. EEMr2 includes a strong melting scenario where the North Dome has strongly retreated resulting in ice-free conditions throughout northern Greenland (including CC) so that the position of NEEM is located at the ice sheet margin. Note that the Eemian ice found in the NEEM ice core is suggested in NEEM community members (2013) to be originally deposited at pNEEM (red dot in Fig. 2), a location much closer to the summit area and NGRIP. Consequently, partially deglaciated conditions during the Eemian at NEEM as used in EEMr2 do not contradict the Eemian ice found in the NEEM core. Further, EEMr2 includes a South Dome which is not connected to the North Dome. The EEMr3 simulation includes the same North Dome as EEMr2, but in addition any South Dome ice (including DYE3) is artificially removed to account for the possibility that southern Greenland was icefree as indicated by Alley et al. (2010). The EEMr4 simulation includes a GrIS which has retreated from the northeast, leaving the northwestern ice core sites (e.g., CC and NEEM) ice-covered. In EEMr4 the saddle between the North and the South Dome still exists but has been narrowed by retreats in central-western Greenland. Note that despite the $1^{\circ}$ resolution the complex topography at the margins (e.g., the fjords) is not well resolved, so the climate in these areas should be treated with caution. As one consequence the small Renland ice dome in eastern Greenland (indicated as REN in Fig. 2), where a deep ice core has been recovered, is not well resolved in the model and thus will not be further analyzed.
Besides the change in Greenland surface conditions (icecovered vs. ice-free), the Eemian melting of the GrIS implemented in the EEMr1-EEMr4 simulations also results in a widespread lowering of the surface elevation compared to present-day (Fig. 3). In EEMr1 the melting from the western margin results in a moderate lowering of the western half of Greenland. The pronounced GrIS retreat in EEMr2 and EEMr3 results in a strong lowering of Greenland's surface, particularly in the areas where the ice is completely removed, i.e., northern and central-western Greenland as well as southern Greenland in EEMr3. A reduction in surface elevation also occurs in the summit region. Thus, all deep ice core sites are located at a lower elevation than in EEMpd. Note also that in EEMr1, EEMr2, and EEMr3 eastern Greenland has higher surface elevations than EEMpd. This is caused by the fact that Robinson et al. (2011) performed transient simulations covering the last two glacial cycles and the GrIS is simulated to be thicker than present-day in eastern Greenland before the Eemian interglacial period. In EEMr4, there is a strong decline in surface elevation in northeastern and central-western Greenland, where all the ice has melted, whereas the summit area almost remains at present-day elevation.

We use the following approach regarding the implementation of the perturbed ice sheets (EEMr1 to EEMr4): in all experiments, we adapt the surface elevation (used by the atmospheric model), the ice sheet thickness, and the surface type (both used in the land component). Therefore, we calculate the differences between the Eemian and present state within the ice sheet model output, interpolate it to our model grid, and add it to the CCSM4 present-day surface elevation. As an example, deglaciated surfaces are set to bedrock elevation and their surface characteristics are set to Arctic tundra. In contrast, the shorelines are unchanged in all experiments as the influence of the Eemian sea level high stand is assumed to be of negligible amplitude. Note that the implemented surface elevation changes have taken into account the isostatic rebound effect. It is also noteworthy that the present-day GrIS used in CCSM4 rather underestimates the Greenland elevations with respect to the real world. Thus, the implemented GrIS is rather too flat, particularly in coastal areas where resolving the complex fjords and valleys is a common issue in virtually all global climate models. Furthermore, the implemented elevation changes are slightly overestimated with respect to ones simulated by the ice sheet models as they are added to the smoothed CCSM4 topography.

\section{Eemian temperature sensitivity}

The reductions of the GrIS in the simulations EEMr1-EEMr4 are substantial both in terms of ice sheet height and area covered as outlined in Sect. 2.4. However, on a hemispheric scale, the implementation of these ice sheets does not lead to a significant response in any climate field (not shown). In contrast, the local changes in Greenland's surface elevation 


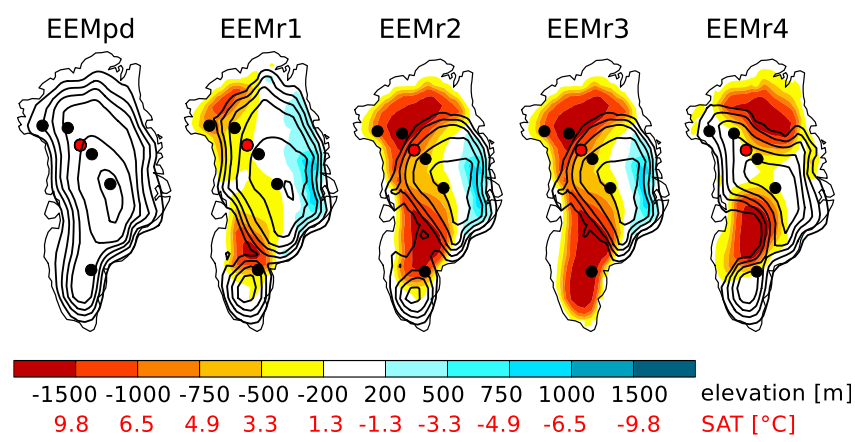

Figure 3. Greenland Ice Sheet topographies implemented in the Eemian sensitivity experiments. Elevation changes from the present-day mask (as used in EEMpd) are shaded (m) and the absolute surface elevation is shown in contour lines (contour interval is $500 \mathrm{~m}$ ). The red scale quantifies the equivalent SAT change in terms of lapse rate $\left(+0.65^{\circ} \mathrm{C}\right.$ per $100 \mathrm{~m}$ decrease in surface elevation).

and ice cover have a distinct impact on the local surface climate, particularly on SAT, which is shown in Fig. 4.

The most striking features of the SAT response to GrIS changes are the spatial variability and its distinct seasonality. The SAT anomalies caused by changes in the GrIS topography over Greenland itself are of large amplitude. For example, in some newly deglaciated near-coast areas in northern Greenland we find a strong winter cooling of over $12^{\circ} \mathrm{C}$, whereas in the same or adjacent inland areas we find a $12{ }^{\circ} \mathrm{C}$ warming during summer. Outside of Greenland the simulations exhibit rather moderate temperature changes, the most prominent being a widespread winter warming over most of the surrounding ocean and sea ice areas, e.g., Baffin Bay and Denmark Strait. The temperature changes over Greenland are clearly shaped by the implemented GrIS topographies and some distinct features seem to be straightforward to explain, e.g., the strong summer warming in areas which become icefree can be related to increased albedo, whereas other features such as the distinct winter cooling in some coastal areas are rather puzzling and are studied in more detail below.

\subsection{The elevation effect}

As Greenland's surface elevation is not identical in the perturbed simulations (e.g., EEMr1) compared to the reference simulation (EEMpd), local changes in the surface temperature have two possible origins: the effect related to a local change in surface elevation and the effect due to a change in local climate, respectively. The elevation effect alters SAT approximately with $-\Gamma \times \Delta z$, where $\Gamma$ is the free atmospheric lapse rate and $\Delta z$ is the change in surface elevation. For each simulation and Greenland grid point we calculate the mid-tropospheric lapse rate $\Gamma$ from the local vertical temperature profile. The resulting values for $\Gamma$ are in all cases close to the normal atmospheric conditions of $0.65^{\circ} \mathrm{C}$ per $100 \mathrm{~m}$. As the elevation changes in the sensitivity ex- periments cover a range of about $-2000 \mathrm{~m}$ to $+750 \mathrm{~m}$, the elevation effect locally accounts for temperature anomalies ranging from about $+13{ }^{\circ} \mathrm{C}$ to $-5^{\circ} \mathrm{C}$ (Fig. 3). If the elevation effect was the only important process for the simulated Greenland SAT sensitivity, the anomalies in Fig. 4 should scale with the elevation anomalies observed in Fig. 3; i.e., all areas with lower (higher) surface elevation should experience a local warming (cooling). However, the comparison of Figs. 3 and 4 shows that this is obviously not the case, and moreover the SAT sensitivity in Fig. 4 shows very different signals during the winter (DJF) and the summer (JJA) season. The distinct seasonality can definitely not be explained with a change in surface elevation and, consequently, the "climate effect" has to be of considerable magnitude.

\subsection{The climate effect}

To quantify the SAT change associated with this climate effect we calculate the lapse-rate-corrected SAT anomalies. In doing so we subtract the elevation-related temperature effect $(-\Gamma \times \Delta z$, shown with red scale in Fig. 3$)$ from the total temperature anomalies found in Fig. 4; so we (virtually) bring all SAT values on Greenland's present-day surface elevation. The resulting lapse-rate-corrected SAT anomalies (Fig. 5) exhibit very different signals for winter and summer climate, confirming that the observed seasonality in SAT sensitivity in Fig. 4 has to be attributed to considerable changes in Greenland surface climate.

The winter climate response to changes in the ice sheet topography is spatially very diverse. We find a distinct cooling (at some locations up to $-12{ }^{\circ} \mathrm{C}$ ) in areas that become flat and ice-free, whereas some areas located on the remaining ice dome are warmer. The strongest cooling is found at locations which were originally located on the steep slopes (e.g., the $\mathrm{CC}$ ice core site in EEMr2) but are in a flat terrain outside of the GrIS in the sensitivity experiment. Regions which are newly placed in the proximity of the ice sheet margin instead of a relatively flat location on the ice dome (e.g., pNEEM in EEMr2), reversely, are warmer than in the reference simulation. Thus, the local terrain and the position on the ice sheet (margin vs. dome) seem to have a crucial impact on Greenland's winter lapse-rate-corrected temperatures.

The summer climate response is dominated by a widespread warming in the newly deglaciated areas. In some regions a moderate but significant warming also occurs on the remaining ice sheet, mostly in locations with rather low elevation and positioned close to the margin (e.g., CC in EEMr4). However, if the ice dome remains of remarkable size (as in EEMr1) the high-elevation locations on the ice dome (e.g., all ice cores in the summit area) experience no significant temperature change. Somehow surprisingly, the removal of the South Dome in EEMr3 does not result in a local summer warming, and at the southwestern coast even a weak cooling is observed. 

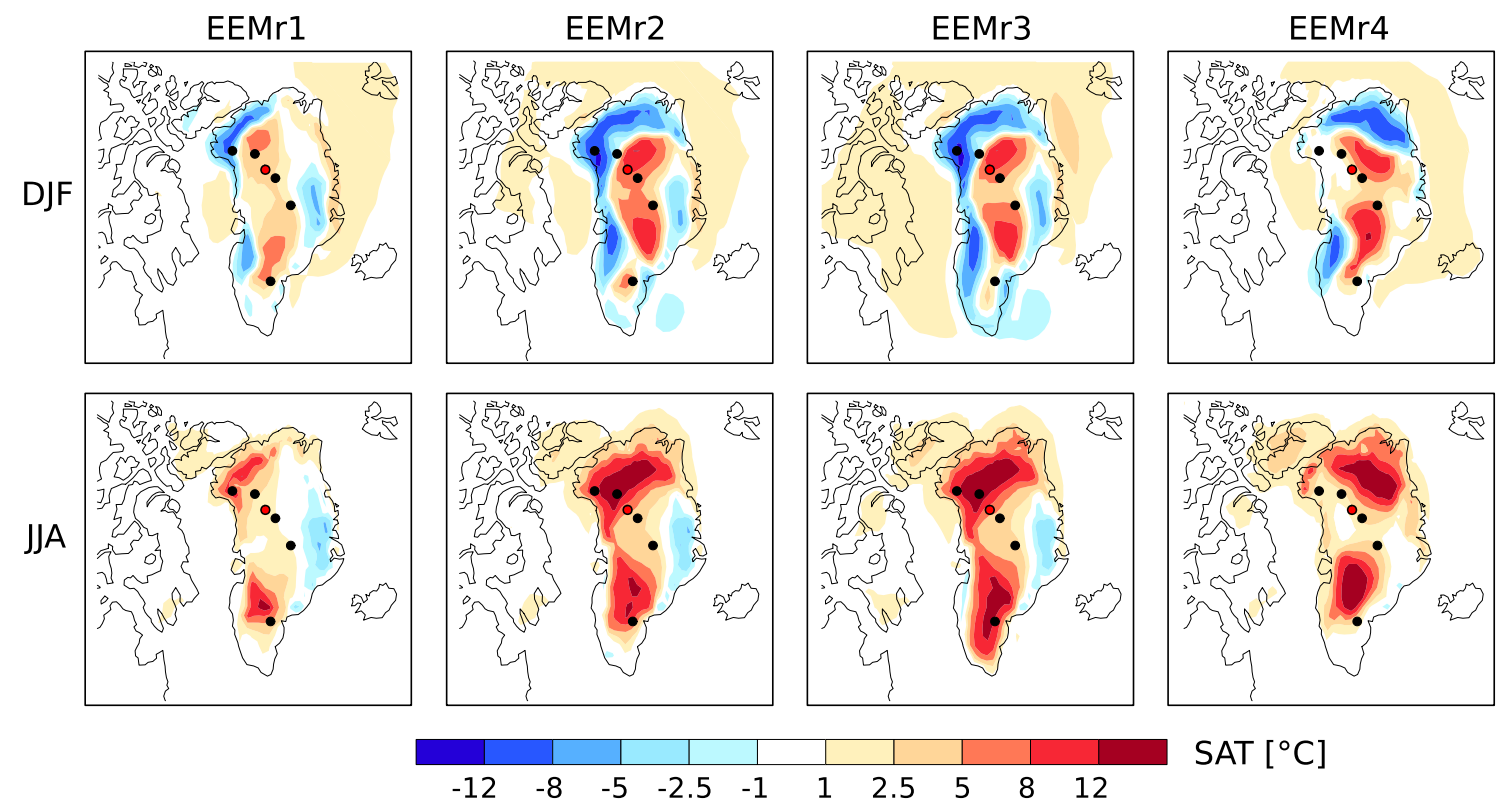

SAT $\left[{ }^{\circ} \mathrm{C}\right]$

Figure 4. SAT anomalies $\left({ }^{\circ} \mathrm{C}\right)$ from EEMpd in the perturbed Eemian simulations over and around Greenland for DJF and JJA.
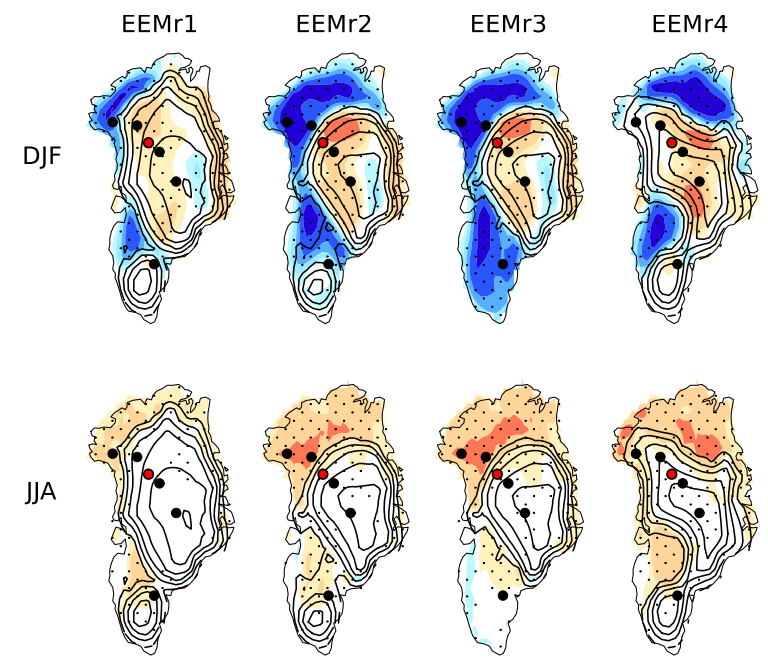

$\begin{array}{llllllllllll}-12 & -8 & -5 & -2.5 & -1 & 1 & 2.5 & 5 & 8 & 12 & \text { SAT }\left[{ }^{\circ} \mathrm{C}\right]\end{array}$

Figure 5. Lapse-rate-corrected SAT anomalies $\left({ }^{\circ} \mathrm{C}\right)$ from EEMpd in the perturbed Eemian simulations over Greenland for DJF and JJA. Black isolines denote the ice sheet surface elevation $(500 \mathrm{~m}$ contour interval) in the corresponding simulation. Stippling denotes significant temperature anomalies at the $5 \%$ level based on $t$ test statistics.

The considerable anomalies in lapse-rate-corrected SAT ask for distinct changes in the processes governing Greenland's surface climate. These processes can either be of dynamical or thermodynamical nature. Changes in atmospheric dynamics, i.e., a rearrangement in the atmospheric flow, could transport large amounts of cold/warm air masses to a Greenland region. Alternatively, the temperature anomalies are related to thermodynamical processes, i.e., changes in the surface heat fluxes due to changes in surface properties or cloud cover, which then locally produce a temperature anomaly. The complex spatial structure in the Greenland SAT anomalies and the fact that we do not find significant temperature changes outside of Greenland (Fig. 4) point to a crucial role of thermodynamical processes which locally react to the altered topography and surface conditions on Greenland itself. In the next two sections, we present in detail the sensitivity of atmospheric circulation and the surface energy balance to changes in the GrIS topography to assess their role for the distinct temperatures anomalies.

\section{Sensitivity of atmospheric circulation}

\subsection{Atmospheric circulation in EEMpd}

The winter large-scale circulation in EEMpd in terms of SLP is dominated by the Icelandic low, which is centered southeast of Greenland (see DJF shading in Fig. 6). The cyclonic winds associated with the low-pressure system produce strong onshore winds striking Greenland's southeastern coast, making this region the wettest of all of Greenland (not shown). Over Greenland itself, the very cold temperatures over the ice dome favor a high-pressure system, known as the Greenland anticyclone (Hobbs, 1945). Thus, the air masses in the lower troposphere encircle the GrIS clockwise, which can be observed in the surface wind field (Fig. 7 top left). The strongest surface winds are found over the steep margins of the GrIS, where the winds are accelerated downslope. 
This air flow of cold air masses descending from the highelevation ice sheet is also known as katabatic wind. The katabatic force which is responsible for these downslope winds is driven by gravity. In addition, these winds are strengthened by the pressure gradient between the very cold ice dome and the relatively warmer regions located at the ice sheet margins, i.e., a thermal wind forcing. In agreement with Steffen and Box (2001) we find that the katabatic winds dominate the low-level wind regime over the GrIS in our model. The mean surface winds, thus, result in a clear outflow of air from Greenland whereby the downslope winds are deflected to the right due to the Coriolis force. The surface winds during winter are particularly strong in northwestern Greenland where the pressure gradient resulting from the low-pressure system over Baffin Bay coincides with the katabatic force (Heinemann and Klein, 2002).

During summer the large-scale circulation in EEMpd exhibits a much weaker pressure pattern (see JJA shading in Fig. 6) generally resulting in a slower atmospheric circulation compared to the winter season. The SLP distribution in the NH mid- and high latitudes results in westerly flow across the North Atlantic. The low-pressure system over northeastern Canada and Baffin Bay enhance the westerly onshore flow towards Greenland. As in winter, over Greenland itself the surface winds are deflected in the Greenland anticyclone, resulting in northward (southward) flow in western (eastern) Greenland (Fig. 7). Also the Greenland surface wind velocities in summer are generally lower than in winter, which can be attributed to the strength in the katabatic forcing (Ettema et al., 2010), as in winter strong radiative cooling over the high-elevation ice dome results in a larger amount of cold dense air masses which are accelerated downslope. Overall, the local and large-scale circulation simulated in EEMpd are in good agreement with previous studies describing the present atmospheric flow over and around Greenland based on observations (Steffen and Box, 2001; Heinemann and Klein, 2002) or climate models (Ettema et al., 2010; Hakuba et al., 2012).

\subsection{Atmospheric circulation with reduced GrIS}

The SLP field across the North Atlantic during both the winter and summer seasons exhibits a high degree of consistency throughout the sensitivity experiments. This means that there is no pronounced rearrangement of the large-scale flow induced by any of the implemented ice sheets. During winter, the sensitivity effect associated with a reduced GrIS generally leads to a weak strengthening of the Icelandic low (shown for the most drastic GrIS reduction, i.e., EEMr3, as contour lines in Fig. 6); however, these anomalies are not significant. For EEMr3 we find some significant lowering of SLP over Baffin Bay, but the anomaly is of moderate amplitude. Previous sensitivity studies showed that a substantial flattening or even a complete removal of the GrIS eventually results in a significantly weaker Icelandic low (Petersen

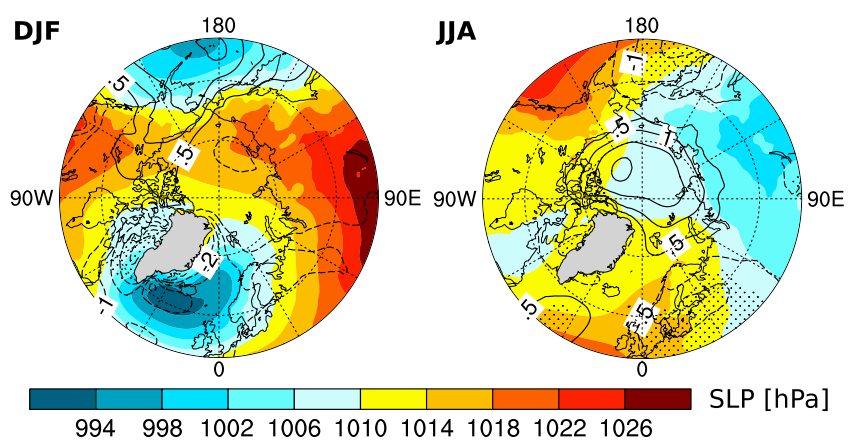

Figure 6. DJF and JJA SLP (hPa) in EEMpd and EEMr3. Shading denotes absolute SLP in EEMpd, contour lines the EEMr3-EEMpd SLP, and stippling where these anomalies are significant at the $5 \%$ level based on $t$ test statistics. The contour interval is $0.5 \mathrm{hPa}$, negative values are dashed, and the zero line is not shown. Note also that SLP values are omitted over Greenland to avoid artifacts emerging from the implemented changes in the GrIS topography.

et al., 2004; Hakuba et al., 2012) as the formation of the "lee cyclone" downstream of southern Greenland is reduced. In our simulations, even in EEMr3 excluding South Dome ice completely, this is not observed.

In summer, the SLP pattern ensuring a westerly flow towards Greenland and across the North Atlantic remains unchanged in all sensitivity simulations (not shown). As in winter, there is a small but significant SLP decrease over Baffin Bay in EEMr3 compared to EEMpd (see contours in Fig. 6). Additionally, a reduced GrIS also results in a SLP decrease over Europe weakening the meridional pressure gradient and slightly lowering the westerly wind strength downstream of Greenland. The atmospheric flow is further investigated in terms of other fields (winds, geopotential height, etc.) across the whole $\mathrm{NH}$ troposphere. However, there are no major changes in any of these fields and at any level outside of Greenland itself, suggesting that the $\mathrm{NH}$ atmospheric planetary flow is robust against the implemented changes in the GrIS topography.

In contrast to the large-scale flow, the low-level winds over Greenland react very sensitively to changes in the GrIS topography (Fig. 7). In both seasons of all experiments we find the anticyclonic flow around the cold ice dome; however, in the perturbed experiments where the GrIS extent is reduced, the Greenland anticyclone becomes smaller as well and the wind velocities decrease. In the EEMr2 experiment, where we implement separated North and South Dome (Fig. 2), we observe an anticyclone above each of the ice domes. In addition, the area of strongest surface winds follows the ice sheet margin (e.g., compare EEMpd and EEMr3 in Fig. 7) since the steep slopes have the largest katabatic potential (Heinemann and Klein, 2002). In contrast, the areas which become flat and ice-free (e.g., northern Greenland in EEMr2) experience a drastic reduction in surface wind speed. In some northern Greenland regions in EEMr2, EEMr3 and EEMr4 the local 


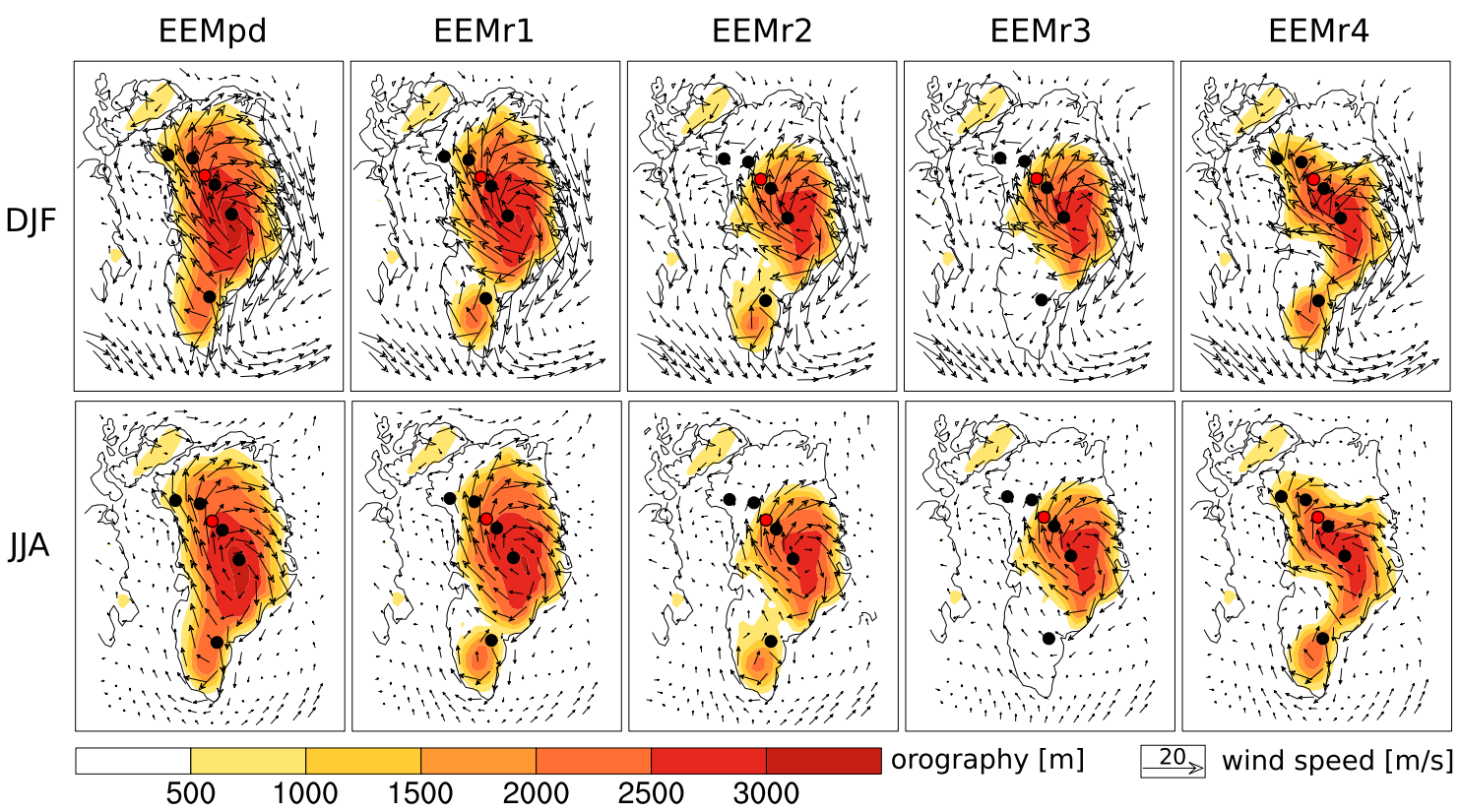

Figure 7. DJF and JJA Greenland surface winds (taken at the lowest terrain-following model level) in the Eemian simulations. The vector length scales with the wind velocity $\left(\mathrm{m} \mathrm{s}^{-1}\right)$. The shading denotes the local surface elevation (500 $\mathrm{m}$ contour interval).

wind vectors over the flat terrain even suggest an inflow of air masses from the Arctic ocean contrary to the typical outflow as found for EEMpd. Consequently, these ice-free areas are no longer influenced by the Greenland anticyclone and the katabatic flow. Hence, some of the Greenland regions with the strongest surface winds in EEMpd (e.g., in northwestern Greenland) become areas with the lowest mean wind speed during all seasons. As we will discuss in detail in Sects. 5 and 6 , these major changes in surface winds also affect the local turbulent heat fluxes.

The slowdown of the katabatic flow in the deglaciated regions is caused by three reasons: (1) the absence of surface slope in the flat terrain, (2) a decrease in the katabatic force as over the deglaciated area a pool of cold air forms that weakens the temperature and pressure gradient between ice dome and ice-free areas, and (3) an increase in surface friction. The latter is particularly relevant during summer, when we observe an impact of the surface type change as the surface roughness of tundra is higher than ice. In winter, this increase in surface roughness is negligible as an extensive snow cover over both tundra and ice surfaces results in similar friction conditions. However, we find that the katabatic wind system dissipates after crossing the GrIS margins during all seasons. This is in agreement with Ettema et al. (2010), who found the same surface wind characteristics over present-day icefree Greenland areas in a regional climate model.

The influence of the Greenland topography on the lowlevel winds is very local. Outside of Greenland we do not find strong changes of the low-level wind field as the local boundary conditions, i.e., sea ice cover and SSTs, in the ocean areas surrounding Greenland are the same in all EEM simulations (Fig. 7). Over Greenland we observe a distinct signal in the local winds throughout the lower troposphere, namely between the surface and the sixth model level (ca. $700 \mathrm{hPa}$ ). Across these levels the wind anomalies associated with changes in the GrIS topography are mostly uniform, i.e., showing the slowdown of the Greenland anticyclone in the lower troposphere. As expected, the changes in the local topography most distinctly translate into wind anomalies at the lowest levels, whereas with increasing height the adaption of the wind field to the reduced GrIS is smaller. In the mid- and upper troposphere (above $500 \mathrm{hPa}$ ), the influence of Greenland's topography on the atmospheric flow is negligible; e.g., there is no formation of a Greenland anticyclone at these levels. The mid- and upper-level flow is shaped by the large-scale geopotential pattern which is observed to be insensitive to changes in the GrIS topography (not shown).

As we do not find a major effect of the GrIS topography on the large-scale atmospheric circulation, a dynamical forcing of the distinct Greenland lapse-rate-corrected temperature anomalies found in the sensitivity experiments (Fig. 5) can be ruled out. This is confirmed by a comparison with SLP and SAT anomalies invoked by the orbital forcing (described in Sect. 2.3). For EEMpd-PI (Fig. 1) we find stronger changes in the large-scale flow than in any of the sensitivity experiments but no corresponding changes in the Greenland temperature pattern. Consequently it is very unlikely that the minor SLP anomalies in the ice sheet sensitivity experiments account for the strong local temperature anomalies 
over Greenland. Support comes also from Lunt et al. (2004), who found that large-scale circulation changes in their "noGreenland-simulation", a scenario much stronger than our perturbed experiments, are not important for the changes in Greenland SAT during both the winter and summer season.

\section{Sensitivity of Greenland's surface energy balance}

The surface energy balance is an important driver of surface temperature on the GrIS. The corresponding surface heat fluxes are compared for two ice core sites, CC and pNEEM (shown in Fig. 2). To this end we average the heat fluxes over the $3 \times 3$ grid points which are located closest to the corresponding ice core site. CC is representative for a Greenland location relatively close to the present-day ice sheet margin which becomes deglaciated in some sensitivity simulations. In detail, the percentage of the grid cells taken as $\mathrm{CC}$ are covered by land ice to $90 \%$ in EEMpd, $25 \%$ in EEMr1, $0 \%$ in EEMr2 and EEMr3, and $33 \%$ in EEMr4. In contrast, pNEEM is representative for an ice core located on the high plateau and remaining completely glaciated throughout all Eemian simulations.

The simulated sensitivity of the annual cycles in surface heat fluxes at these two ice core sites is shown in Fig. 8. We thereby quantify the different heat flux components, namely net downward shortwave (SWnet), net downward longwave (LWnet), sensible heat (SHF), and latent heat (LHF) in the Eemian simulations. Note that EEMr3 is not included in Fig. 8 as it shows an almost identical response of the surface heat fluxes to EEMr2 because both simulations have the same GrIS topography and surface conditions at CC and pNEEM. Note also that the representation of the surface turbulent fluxes of momentum, water, and sensible heat are obtained using bulk formulas in CAM4.

\subsection{Surface heat fluxes in EEMpd}

The surface heat fluxes in EEMpd (black line in Fig. 8) show similar values for CC and pNEEM as both ice core sites are located on the present-day GrIS. The bright surface of the GrIS has a high albedo and, hence, reflects a substantial part of the incoming shortwave (SW) radiation. The highlatitudinal position of Greenland further leads to the distinct seasonal cycle in SWnet. Both ice core sites constantly lose heat through LWnet, and this heat loss surpasses the absorption of SW radiation, so the net surface radiation balance is negative on annual average. Particularly in winter during the absence of sunlight, the longwave (LW) heat loss dominates, leading to a strong cooling of Greenland's surface and resulting in a very stable stratification of the atmospheric boundary layer (Hoch et al., 2007). Accordingly, we find a distinct inversion layer above both ice core sites during the winter months (not shown). Negative surface radiation has to be compensated by turbulent heat fluxes. As Greenland is marked by rather dry conditions and little snowfall (which would result in a LHF signal) most of this heat flux compensation is provided by sensible heat. The positive SHF for EEMpd at CC and pNEEM indicates heating of the surface at the cost of a cooling in the atmospheric boundary layer. The positive turbulent SHF is most effective in areas where high values of turbulent momentum coincide with a heat deficit induced by the radiative cooling (Ettema et al., 2010). Thus, the highest SHF is found during winter in the katabatic wind zones, i.e., in the regions of the ice sheet margins, which is also in agreement with SHF measurements by van den Broeke et al. (2005). As a consequence we observe a stronger SHF at CC than at pNEEM in the EEMpd simulation. During the summer season, the larger energy input through SW radiation minimizes the radiative surface cooling, resulting in a smaller temperature deficit of the surface compared to the overlying boundary layer (not shown). In addition, the surface winds during summer are slower compared to winter (Fig. 7) and hence SHF is clearly reduced during the summer months at both ice core sites (Fig. 8).

\subsection{Surface heat fluxes with reduced GrIS}

Comparing the surface heat fluxes at $\mathrm{CC}$ among the different Eemian simulations (Fig. 8 top row), we find considerable sensitivity during all seasons. During the winter months, there is a distinct response in LWnet and SHF to changes in the GrIS topography. In contrast, the absence of solar insolation in polar winters (obviously independent of the GrIS) keeps SWnet at zero levels in all simulations. Further, LHF is negligibly small in winter as the cold and dry climate in all Eemian simulations does not foster moist processes such as snow deposition or sublimation. In EEMr1 and even stronger in EEMr2 the SHF is strongly reduced compared to EEMpd, which is likely coupled to the decrease in surface wind speed as CC is located at a flat, ice-free location outside of the katabatic wind regime (see EEMr2 wind vectors in northwestern Greenland in Fig. 7). The absence of turbulence reduces the magnitude of the winter SHF at CC from about $45 \mathrm{~W} \mathrm{~m}^{-2}$ in EEMpd to approximately $30 \mathrm{~W} \mathrm{~m}^{-2}$ in EEMr1 and to $20 \mathrm{~W} \mathrm{~m}^{-2}$ in EEMr2. This leads to the strong local winter cooling found in Fig. 5, and correspondingly the surface at $\mathrm{CC}$ emits less heat through $\mathrm{LW}$ radiation in EEMr1/EEMr2 than in EEMpd (LWnet in Fig. 8 top row). Comparing the downward and upward component of LW radiation (not shown) it becomes clear that changes in LWnet are dominated by changes in the upward component, supporting our concept that the SHF is the driver of the winter temperature sensitivity rather than processes governing the downward LW radiation. In the EEMr4 simulation, CC is still located in the ice sheet margin area subject to strong winds (see EEMr4 in Fig. 7). Consequently, there is no substantial change in SHF, lapse-rate-corrected SAT, and LWnet in EEMr4 with respect to EEMpd. Note that a reduced surface wind speed and the associated surface cooling also lead 

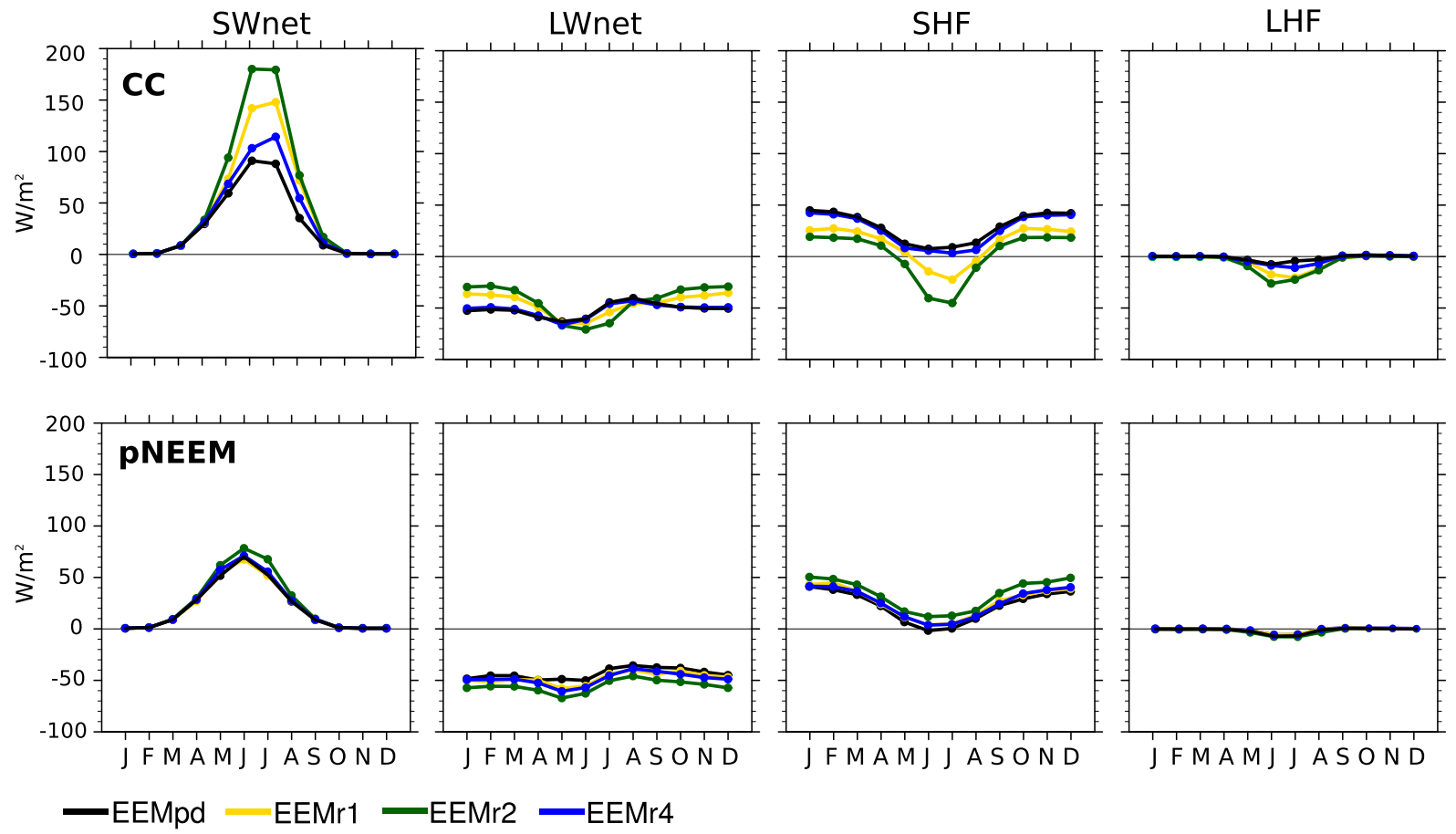

Figure 8. Annual cycle of surface heat fluxes $\left(\mathrm{W} \mathrm{m}^{-2}\right)$ at Camp Century (CC, top) and pNEEM (bottom). The sign convention is positive into the surface. Note that EEMr3 is not shown as it is basically the same as EEMr2 as these two simulations include the same GrIS topography and surface conditions at $\mathrm{CC}$ and pNEEM.

to a substantial stabilization of the low-level atmosphere in the form of a strong thickening of the inversion layer (not shown).

Similar to CC the contributions of LHF and SWnet to the surface energy balance at pNEEM (Fig. 8 bottom row) are negligible during the winter months. However, SHF reacts to changes in the surface wind speed, which gets stronger in all perturbed EEM simulations as with a reduced GrIS pNEEM is located closer to the ice sheet slopes (Fig. 3). The increased energy input into the surface through SHF is reflected in a significant lapse-rate-corrected winter warming at pNEEM (Fig. 5). The surface energy budget is balanced as the warmer SAT leads to an increase in outgoing LWnet. Complementary to the response at $\mathrm{CC}$ we identify a weakening of the winter inversion at pNEEM in the perturbed EEM simulations (not shown) as surface temperatures are warmer and the enhanced wind turbulence favors vertical mixing.

The sensitivity to GrIS topography of the surface energy balance at CC during the summer months is dominated by strong changes in SWnet from the EEMpd levels (Fig. 8 top left). Whereas during spring and autumn an almost complete snow cover (not shown) hides the surface changes associated with the (partial) deglaciation at CC, the relatively dark tundra surface is exposed to the atmosphere during the summer months and leads to a substantial decrease in surface albedo between May and September. As a result, we find a strong increase in SWnet radiation for the completely ice-free condi- tions in EEMr2 (and EEMr3), whereas the partially glaciated conditions in EEMr4 (33\% ice cover) and EEMr1 (25\% ice cover) lead to a more moderate increase in SWnet. The additional energy input through increased SW absorption further leads to a significant local summer warming (in EEMr1, $\mathrm{EEMr}$ 2, and EEMr3) at CC (Fig. 5) and also to changes in all other components of the surface energy balance. As directly determined by the Stefan-Boltzmann law, the warmer surface temperatures lead to stronger heat loss through LW radiation (see LWnet during summer months in Fig. 8 top row). Moreover, the additional energy input through SW radiation is further compensated by increased heat loss through the turbulent fluxes. In EEMpd the cold ice surface at CC results in an input of sensible heat from the atmospheric boundary layer even during the summer months. However, in EEMr1 and EEMr2 the surface warming translates into a transition from positive (heat input towards the surface) to a negative (heat loss of the surface) SHF. The heat loss by SHF comes along with an increase in LHF. In EEMr1, EEMr2, and EEMr3 the warm summer conditions at $\mathrm{CC}$ lead to a complete melting of the winter snow and all summer precipitation falls in the form of rain instead of snow (not shown). Hence, these moist and warm conditions at an ice-free CC foster heat loss through evaporation as displayed by the LHF. In addition, the strong melting of snow in low, ice-free regions (such as CC) itself makes a contribution to the surface 
energy balance (not shown) as it consumes a considerable amount of energy available from the strong SW input.

On the remaining ice dome, illustrated for pNEEM, we observe a more moderate response of the summer surface heat fluxes than at CC (Fig. 8). SWnet is slightly increased in EEMr2 and EEMr4 compared to EEMpd during the summer half-year coming along with a slight decrease in albedo (not shown). The origin of this albedo decrease is twofold. On the one hand the cloud cover over pNEEM is decreased in EEMr2 and EEMr4 (not shown), allowing more downward SW radiation to penetrate through the atmosphere and to arrive at the surface. On the other hand, we find increased snow melting during July and August at pNEEM (not shown), which darkens the ice surface, thereby contributing to the increase in SW absorption. The pNEEM surface in the simulations with a reduced GrIS also receives increased energy input through downward SHF. This effect is analogous to the described SHF changes during the winter months and closely tied to the increase in surface wind speed as the pNEEM location is shifted towards the GrIS margin. The additional energy input results in a surface warming; however, the lapserate-corrected summer warming at pNEEM is of smaller amplitude than during the winter. In order to close the surface energy budget in the perturbed Eemian experiments, the warmer surface temperatures at pNEEM result in increased emission of LW radiation throughout the year, whereas the small heat loss through LHF remains approximately constant among all sensitivity experiments. For EEMr3 the increased energy input through SWnet and SHF is also partly compensated by enhanced surface melting (not shown).

The response of the surface energy balance in a scenario with ice-free conditions on Greenland has been previously tested by Toniazzo et al. (2004). Their simulated response in surface heat fluxes to a complete removal of the GrIS is in good agreement with our simulated response for ice-free conditions, e.g., as shown for EEMr2 at CC. This emphasizes that the results for an ice-free $\mathrm{CC}$ are at least partially representative for all Greenland regions which became icefree during the Eemian. Toniazzo et al. (2004) also agree that deglaciated regions experience a stronger warming in summer than in winter, induced by the decrease in summer surface albedo. In contrast, they do not discuss in detail the changes in winter SAT and their relation to the changes in winter surface heat fluxes. From our simulations it appears clear that the spatially diverse winter SAT changes related to the climate effect (shown in Fig. 5) have their origin in changes of the local surface energy balance.

\section{Influence of GrIS topography on Eemian temperature at ice core sites}

The sensitivity of Greenland's climate to changes in the GrIS topography exhibits strong spatial variability. Hence, two Eemian temperature reconstructions from two different
Greenland ice core locations likely include different topography signals that are more complex than a simple lapse rate correction for different elevation changes. Therefore, we show the dependence of the most important surface variables driving the local lapse-rate-corrected SAT at the main deep ice core sites on the choice of the GrIS topography. We compare the five deep ice core sites (CC, NEEM, NGRIP, GRIP, and DYE3) and the location pNEEM, the latter being particularly interesting as it can be compared with the Eemian temperature reconstruction by NEEM community members (2013). Connecting these ice core sites, we construct a Greenland transect (Fig. 9d) which largely follows the ice divide.

The profile of surface elevation (Fig. 9a) for the presentday GrIS in EEMpd shows that the transect connects the large North Dome (peaking at GRIP) with the South Dome (peaking near DYE3) through a high-elevation ridge. The comparison of the EEMpd elevation with the measured elevation at the ice core sites in the real world, indicated by black stars, shows that Greenland in CCSM4 is rather too flat. The strongest underestimation is found at $\mathrm{CC}$ where the model smooths out the complex coastal topography. However, the EEMpd elevation at the other deep ice core sites matches the real elevation sufficiently well.

The retreated ice sheets in EEMr1-EEMr4 generally result in lower elevations throughout the transect (Fig. 9a). As the volume loss is strongest close to the margins, the ice sheet slopes are generally steeper and move inland towards the main ice domes. The elevation of the summit area (region around GRIP) remains at high elevation (always above $2500 \mathrm{~m}$ ) in all simulations. An additional major feature of the retreated GrIS topographies is the substantial lowering of the ridge between GRIP and DYE3, which creates longer and steeper slope areas in between.

\subsection{Winter mechanism}

For Greenland winters we have suggested in Sect. 5 that the energy input through SHF is crucial for the local winter SAT. As the SHF strongly depends on turbulence in the boundary layer induced by low-level winds, any changes in GrIS topography adapting the surface wind field can result in a strong topography-driven temperature signal. Indeed, the profiles of DJF surface wind speed (Fig. 9b) and SHF (Fig. 9c) along the ice core transect indicate a clear relationship to the elevation profile shown in Fig. 9a. As the surface winds depends on the slope, the DJF wind profile roughly scales with the first derivative in surface elevation (compare Fig. 9a and b). Further, the SHF is linearly related to turbulence, so an approximately linear relationship between the DJF wind and SHF profiles can be found (compare Fig. 9b and c).

In EEMpd, the long slope from the start of the transect up to the summit area around GRIP is consequently accompanied with strong surface winds, whereas in the flatter summit 

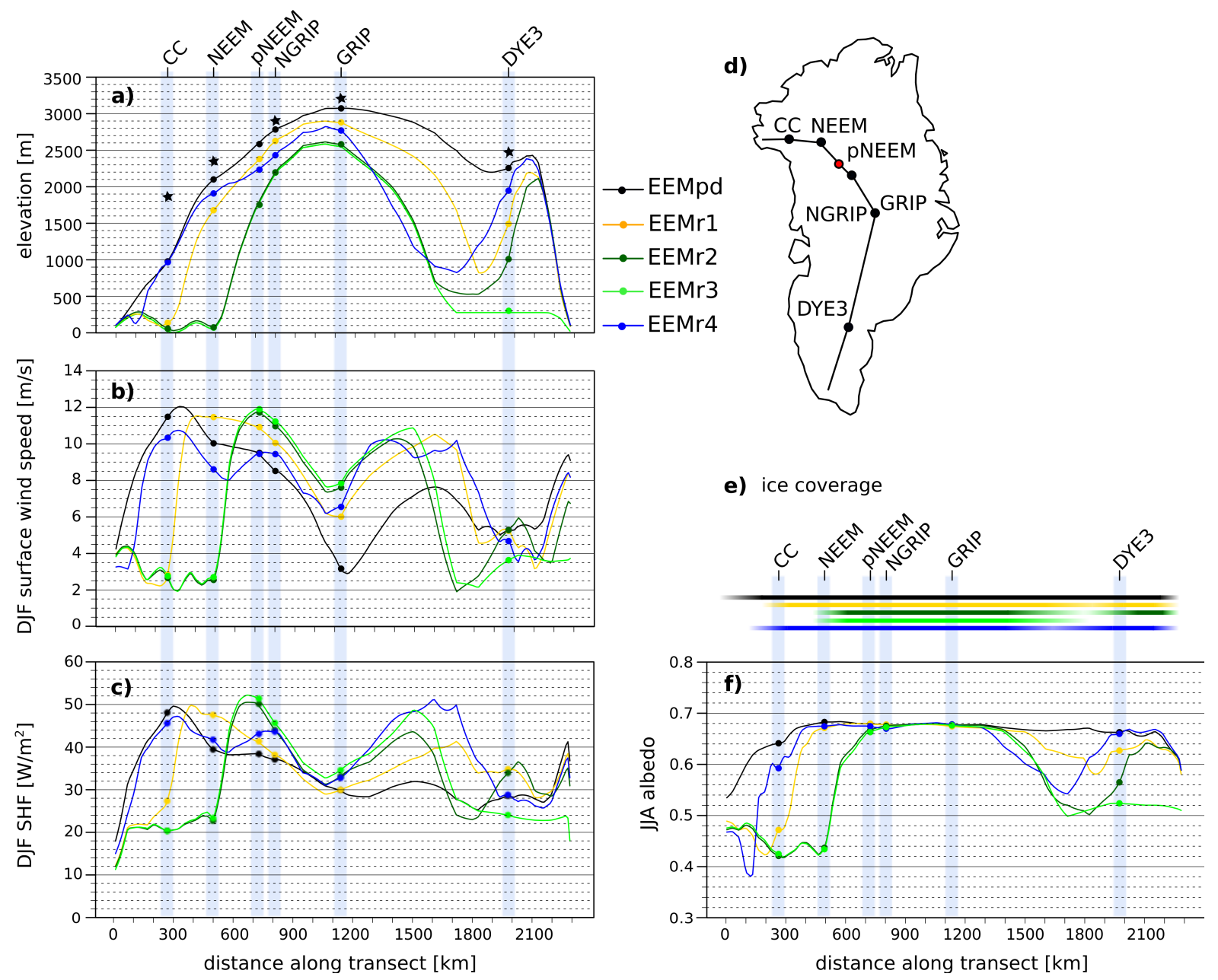

Figure 9. Profiles of (a) surface elevation (m), (b) DJF wind speed $\left(\mathrm{m} \mathrm{s}^{-1}\right)$, (c) DJF SHF (W m ${ }^{-2}$ ), (e) ice coverage, and (f) JJA albedo along the Greenland transect shown in (d) in all Eemian simulations. The transect connects the ice core sites of Camp Century (CC), NEEM, pNEEM, NGRIP, GRIP, and DYE3 from north to south. The black stars in (a) indicate the present-day elevations of the ice core sites in the real world. Bars in (e) show which part of the transect is covered by land ice, whereby partly transparent filling indicates partial ice coverage and opaque filling indicates complete ice coverage.

area the wind velocities are lower. Further, the surface wind maxima and minima approximately coincide with equivalents in SHF, i.e., a clear maxima in SHF near CC. Note that the magnitude of the SHF is not solely driven by the strength of the turbulence but also depends on temperature difference between the surface and the overlying air masses. Hence, the DJF wind speed and SHF profiles do not completely correspond to each other, e.g., the damped EEMpd SHF minimum around GRIP compared to distinct minimum in GRIP surface wind speed originates in a strong local temperature deficit of the surface air layers compared to the surface temperature (not shown). This particularly strong temperature inversion above the GrIS summit area fosters SHF despite the low local wind speed in EEMpd.

Comparing the profiles among the Eemian sensitivity simulations, we also find the abovementioned relationship be- tween the position and strength of the surface slopes, the strength in surface wind, and the amount of energy input into the surface through SHF. For example, in EEMr1 (compared to EEMpd) the ice sheet margin retreats to $\mathrm{CC}$; thus, the long slope is shifted inland, and connected to these elevation changes also the maxima in winter wind speed and SHF are shifted more inland. At the flat area of EEMr1 CC the wind speed drops and less energy reaches the surface through SHF, whereas the opposite (i.e., increase in wind speed and SHF) is observed at NEEM and to a lower degree also at pNEEM and NGRIP. The even smaller and steeper North Dome in EEMr2 and EEMr3 (Fig. 9a) leads to the same consistent response: at CC and NEEM, which are located outside of the ice sheet margin, wind velocities and SHF are strongly reduced, whereas the opposite signal is detected at the ice cores sites in the summit area - i.e., pNEEM, NGRIP, and GRIP 
- as these regions get closer to the wind-active ice sheet margins. The implemented topography in EEMr4 results in a flatter slope between CC and GRIP (Fig. 9a) and, hence, in lower surface wind velocities. However, the EEMr4 DJF SHF shows little changes compared to EEMpd and around pNEEM and NGRIP even an increase in SHF. This increased heat input in the form of sensible heat is linked to a strengthening in the local surface temperature inversion (not shown). The relationship found between SHF, surface wind speed, temperature inversion and the position/slope on the GrIS is summarized and illustrated in Fig. 10.

The anomalies in DJF SHF in the retreated EEM simulations compared to EEMpd distinctly influence the DJF Eemian-PI lapse-rate-corrected SAT signal at each of the six ice core sites (Fig. 11a). The model simulates almost no temperature change for EEMpd compared to PI, showing that the Greenland winter temperatures in CCSM4 is not very sensitive to the Eemian orbital forcing (as explained in Sect. 2.3). In contrast, the inclusion of a retreated GrIS leads to a substantial change in local SAT. For example at CC, the decrease in DJF SHF for the EEMr2, EEMr3 and EEMr4 simulations shown in Figs. 8 and 9c results in a strong local cooling of up to $-14^{\circ} \mathrm{C}$ in Fig. 11a. Consistently, the SHF reduction forced by the decrease in surface winds also lead to strong cooling in EEMr2 and EEMr3 at NEEM and in EEMr3 at DYE3. In contrast to that, the increase in surface winds leading to a more efficient SHF results in a significant surface warming at the cores near the summit -i.e., pNEEM, NGRIP, and GRIP - in all Eemian simulations containing a retreated GrIS. At NEEM, we find a SHF-related warming for EEMr1 and EEMr4.

\subsection{Summer mechanism}

During the summer season we observe a $3-4{ }^{\circ} \mathrm{C}$ EEMpdPI warming at all ice core sites (Fig. 11b), which is related to anomalously high Eemian summer insolation and, thus, independent of GrIS topography. The implementation of a reduced GrIS (EEMr1-EEMr4) can locally enhance the Eemian summer warming. The strongest warming is found for ice core sites which become completely ice-free, e.g., CC and NEEM in EEMr2 (Fig. 9e). Thus, the deglaciated surface experiences a strong decrease in summer albedo (Fig. 9f) as all snow is melted in summer at these low-elevation sites and the exposed tundra vegetation absorbs more SW radiation than ice. The resulting albedo feedback leads to an additional warming of up to $6^{\circ} \mathrm{C}$ (see difference between EEMr3 and EEMpd at NEEM in Fig. 11b). Comparing the transects of ice coverage and JJA albedo (Figs. 9e and f) we find that any partial or complete reduction in ice cover results in a decrease in summer albedo. This is not the case for the other seasons when an extensive snow cover prevents most of this albedo effect (not shown). Hence the increased warming due to the albedo effect in the EEMr1-EEMr4 simulations is limited to the summer season. Apart from changes in the land

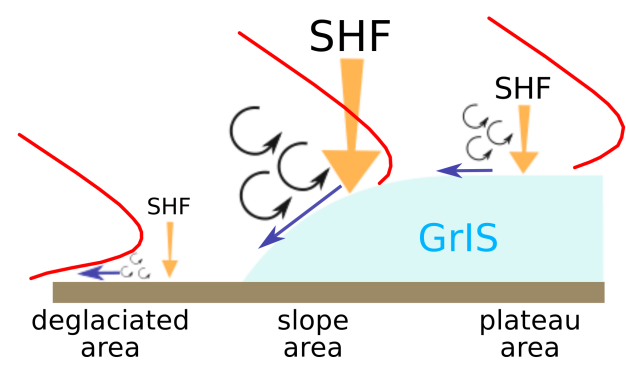

Figure 10. Schematic overview of the sensitive winter processes driving Greenland's surface temperatures as a function of the position and slope on the GrIS. Blue arrows indicate the surface wind velocities, orange arrows the downward SHF, the curly vectors the amount of turbulence, and the red lines the vertical temperature profile. Deglaciated areas are characterized by very weak surface winds and turbulence prohibiting an efficient SHF and resulting in very strong temperature inversion. Slope areas encounter strong surface winds due to the katabatic forcing, inducing strong turbulence and an efficient SHF eventually resulting in relatively warm surface temperatures and a weak inversion layer. The plateau area depicts a somewhat intermediate state with moderate strength in all shown parameters.

ice cover, enhanced summer melting of the snow surface is observed all over the areas at lower elevations, including pNEEM in EEMr2 and EEMr3 (not shown). This surface melting process results in a slight decrease in local albedo, e.g., at pNEEM from 0.68 (EEMpd) to 0.65 (EEMr2), leading to higher SW absorption as shown in Fig. 8. However, this melting-induced albedo effect is of second-order importance compared to the distinct albedo changes based on changes in the surface type.

In the plateau area, we also find an increased energy input trough SHF in the simulations with a reduced GrIS (see SHF during summer months for pNEEM in Fig. 8). The additional summer warming at pNEEM, NGRIP, and GRIP in the retreated EEM simulations compared to EEMpd (Fig. 11b), thus, is likely a combination of increased SHF (related to the winter mechanism described above) and occasionally stronger SW absorption as the retreated GrIS topographies locally foster stronger surface winds and surface melting during the summer season. Interestingly, the albedo decrease at DYE3 in EEMr2 and EEMr3 just results in a small additional warming compared to EEMpd (Fig. 11b) as the additional surface energy input through SW is compensated by a strong loss of surface heat through the turbulent fluxes, namely SHF and LHF (not shown).

\subsection{Implications for Greenland temperature reconstructions}

Our findings suggest that a considerable part of the Eemian Greenland temperature reconstructions for the Eemian interglacial (based on proxy data) might be influenced by contemporary changes in the GrIS topography and accompanied 

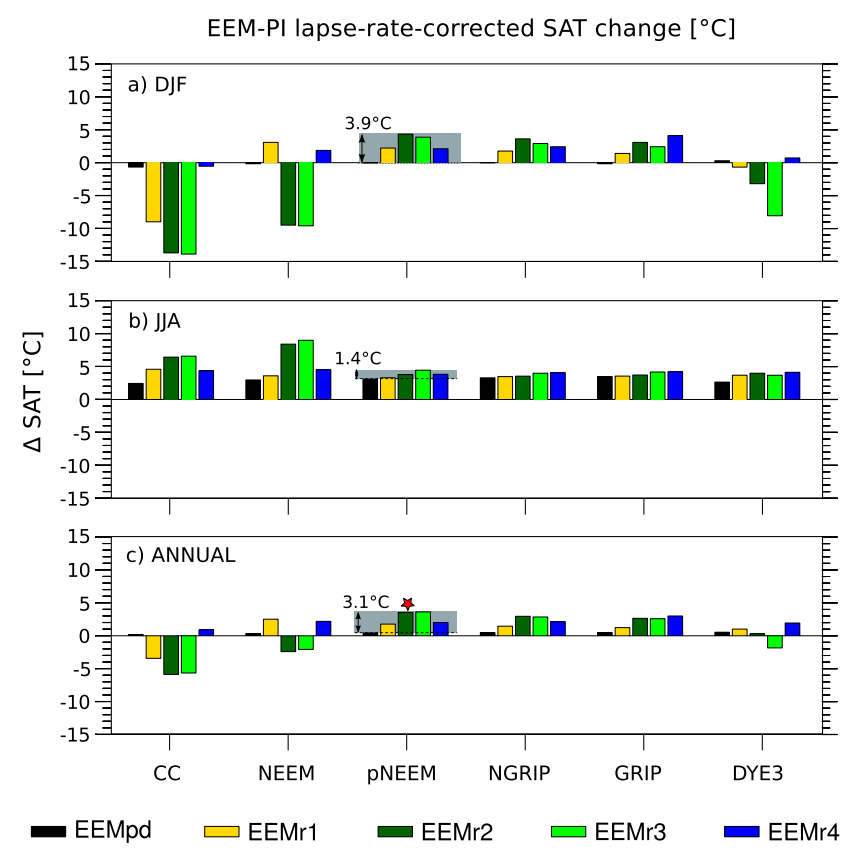

Figure 11. Eemian lapse-rate-corrected SAT anomalies $\left({ }^{\circ} \mathrm{C}\right)$ with respect to pre-industrial (PI) for (a) DJF, (b) JJA, and (c) annual mean at Camp Century (CC), NEEM, pNEEM, NGRIP, GRIP, and DYE3. The gray bars in the pNEEM row indicate the spread among the EEM simulations, whereas the red star indicates the $\delta^{15} \mathrm{~N}$ SAT estimate from NEEM community members (2013).

changes in Greenland's surface climate, which cannot be explained by the lapse rate change only. The implementation of different GrIS topographies in the sensitivity simulations result in a remarkable spread in Eemian-PI lapse-ratecorrected SAT change (Fig. 11). The largest spread is found for CC, NEEM, and DYE3, which are most affected by the shift of the katabatic wind zones and even become ice-free in some simulations. This leads to a very strong local temperature change compared to EEMpd. However, the GrIS topography also has an impact on the Eemian-PI temperature change at sites which remain completely glaciated such as the ice cores sites on the plateau area. For pNEEM, we find that implementing a reduced GrIS can result in a lapse-ratecorrected warming of up to $3.9^{\circ} \mathrm{C}$ for DJF, $1.4^{\circ} \mathrm{C}$ for JJA, and $3.1^{\circ} \mathrm{C}$ in the annual mean (indicated with gray shading in Fig. 11). Note that this topography-related SAT signal is even larger when looking at absolute temperature changes not correcting for the local elevation changes. Hence for pNEEM we find a strong warming of up to $8{ }^{\circ} \mathrm{C}$ in the annual mean notlapse-rate-corrected surface temperature. In all simulations with a retreated GrIS (EEMr1-EEMr4) pNEEM's surface elevation is lower compared to EEMpd (Fig. 9a), so the "elevation effect" consequently acts as an additional source of local warming.

The Eemian temperature estimates, consequently, need to be corrected for this elevation effect. For the NEEM core, air content measurements of enclosed bubbles have been used to estimate changes in local surface elevation (NEEM community members, 2013). However this correction has its limitations as between 127 and $118.3 \mathrm{ka}$ the air content measurements are affected by surface melt, so the air content record for this period has been approximated by interpolating the levels from before and after (see Fig. 4 in their manuscript). Including further strong corrections for changes in local summer insolation that influence the air content record, they propose a rather smooth 127-118 ka transition of pNEEM's surface elevation from $210 \pm 350 \mathrm{~m}$ above present to $130 \pm 310 \mathrm{~m}$ below present and conclude that the Eemian melting of the GrIS has been very moderate. The consequence is a very strong Eemian warming remaining after the lapse rate correction performed by NEEM community members (2013) but comparatively little melting of the GrIS. Note that as described in Sect. 3.1, changes in surface elevation are closely tied to changes in SAT; hence any underestimation of the surface lowering at pNEEM during the Eemian results in an overestimation of the lapse-rate-corrected Eemian temperatures.

A moderate reduction of pNEEM's surface elevation as suggested in NEEM community members (2013) (maximum $440 \mathrm{~m}$ lower than present) is in line with the GrIS implemented in EEMpd, EEMr1, and EEMr4. However, with these setups we observe only a lapse-rate-corrected Eemian-PI annual mean SAT warming at pNEEM of $0.4{ }^{\circ} \mathrm{C}$ (EEMpd), $1.8^{\circ} \mathrm{C}$ (EEMr1), and $1.6^{\circ} \mathrm{C}$ (EEMr4) (Fig. 11c). In contrast, in EEMr2 and EEMr3 the surface at pNEEM is lowered by $750 \mathrm{~m}$ (not in line with NEEM observations), but the smaller GrIS leads to a stronger lapse-rate-corrected Eemian-PI warming of up to $3.5^{\circ} \mathrm{C}$ resulting from both the winter and summer mechanism. The simulated pNEEM warming is compared to the Eemian $\delta^{15} \mathrm{~N}$ signal from the NEEM ice core which indicates that the annual mean Eemian firn temperatures between 128.5 and $114 \mathrm{ka}$ were on average $5{ }^{\circ} \mathrm{C}$ warmer than present (NEEM community members, 2013). Hence, neither of the simulations can reproduce the full magnitude of the Eemian warming observed in the NEEM core (Fig. 11c). Note also that the warming associated with a reduction in the GrIS is likely an effect which occurs during later stages of the Eemian as a substantial ice sheet retreat requires several millennia of interglacial climate conditions (i.e., strong insolation forcing). Thus, the presented sensitivity to GrIS topography cannot explain early peaks in Greenland temperatures during the Eemian, such as the $8 \pm 4{ }^{\circ} \mathrm{C}$ warming at $126 \mathrm{ka}$ suggested by the NEEM $\delta^{18} \mathrm{O}$ record. Moreover, one has to keep in mind that $\delta^{18} \mathrm{O}$ is a measure for condensation temperature determined by the isotopic fractionation process occurring along the moisture pathway. Hence, the presented winter mechanism comprising wind and energy flux processes in the stable boundary layer is unlikely recorded by $\delta^{18} \mathrm{O}$. Consequently, the remarkable $\delta^{18} \mathrm{O}$ peak found at NEEM needs to be explained by other processes. 


\section{$7 \quad$ Summary and conclusions}

Using a comprehensive climate model we have conducted a set of sensitivity experiment to study the influence of a reduced GrIS on the Eemian interglacial climate. Based on these simulations, we have studied in detail the impact of changes in Greenland's topography on the local surface climate, particularly on surface temperature, and its relation to changes in atmospheric circulation and the surface energy balance. The key findings are as follows:

- Greenland's SAT reacts very sensitively to changes in the GrIS topography, both to changes in surface elevation (elevation effect) and to changes in the surface heat fluxes (climate effect). The SAT sensitivity related to the climate effect has a very local signature and exhibits a distinct seasonality.

- Changing the GrIS slopes impacts the strength of the (katabatic) surface winds, which translates into strong lapse-rate-corrected SAT anomalies through changes in the turbulent SHF. This effect is mainly dominant in winter but also of importance during the other seasons.

- Stronger katabatic winds help to warm the surface by breaking up the inversion layer and enhancing vertical SHF.

- In summer, deglaciated areas and regions at low elevations exposed to substantial surface melting experience a distinct surface warming related to a decrease in surface albedo.

- Changes in large-scale circulation are negligible according to all sensitivity experiments.

Our results have two important implications for modeling the GrIS, in particular for the Eemian interglacial. First, the concurrence of the ice margin and high turbulent heat fluxes potentially accelerates melting in warmer climates. This previously disregarded physical mechanism amounts to several tens of $\mathrm{W} \mathrm{m}^{-2}$, comparable to the magnitude of seasonal insolation changes due to Milankovitch forcing. Hence, this finding clearly calls for bi-directional coupling of climate and ice sheet models. Few of the existing studies employ bi-directional coupling, and the ones that do, except Helsen et al. (2013), often use climate models of coarse resolution and simplified physics that do not include the regional Greenland winds. Secondly, the strong increase in reconstructed Eemian surface temperatures at pNEEM is only plausible with a location of the pNEEM site close to the ice edge, within the katabatic wind belt. While this constraint is satisfied by several of the simulated ice topographies used in this study, it raises the question whether the ice margin approached pNEEM from the west (EEMr2, EEMr3) or from the northeast (EEMr4). Considering the evidence of Eemian ice found at Camp Century (Dansgaard et al., 1985), melting from the northeast appears to be the more likely scenario.
The results of this study, furthermore, are relevant for the interpretation of Eemian climate reconstructions based on Greenland proxy archives such as the NEEM ice core. Changing the GrIS topography acts as a local forcing for Greenland's climate, whereas the effect on the climate outside of Greenland is small and mostly negligible. Concerning the Eemian temperature at pNEEM we find that a smaller GrIS can account for up to $3.1^{\circ} \mathrm{C}$ of the Eemian-PI warming. In view of the local nature of the climate effect in our model, the strong Eemian warming found in NEEM ice (NEEM community members, 2013) has at least partly to be regarded as a local effect rather than interpreting the full magnitude as a large-scale climate signal.

The simulated temperature response to changes in the GrIS topography shows particularly local characteristics during the winter season, when the shape of the GrIS determines which areas are (relatively) warmed by the SHF in the katabatic wind zones, in contrast to areas which experience little turbulence and, thus, a strong cooling. However, these results strongly depend on processes within the stable boundary layer and lead to some uncertainty in representing the amplitude of these SAT anomalies as they are sensitive to the details of the boundary layer formulation (Holtslag et al., 2013). In contrast, the Eemian temperature anomalies during the summer months are mostly independent of boundary layer processes. In all simulations, we find a widespread (lapse-rate-corrected) summer warming of 4$5{ }^{\circ} \mathrm{C}$ over Greenland being in agreement with proxy estimates (CAPE Last Interglacial Project Members, 2006) and conforming with observed melt layers in the NEEM ice core (NEEM community members, 2013). Therefore, enhanced summer insolation due to the Eemian orbital parameters is the primary forcing independent of the implemented GrIS. However, the GrIS extent determines which areas become ice-free, thus encountering intensified warming through the albedo feedback. Albedo-related warming is also simulated over glaciated areas (e.g., at pNEEM) that experience surface melting. However, the resulting temperature change is likely underestimated, as the CCSM4 model simulates toolow summer albedo values above Greenland's snow and ice surfaces assuming a present-day GrIS (Vizcaino et al., 2013). Consequently, the potential albedo change through melt water is diminished by this model bias (e.g., our model simulates an albedo increase of 0.03 instead of a more likely increase of 0.15). Nevertheless, our results show that the spatial pattern of Eemian warming over Greenland has likely been very diverse and in order to gain a complete understanding of Greenland's Eemian climate additional climate reconstructions are needed.

Although this sensitivity study includes some scenarios with a strongly melted GrIS, none of the simulations can fully explain the observed Eemian warming reconstructed from the NEEM ice core. Moreover, to experience the strongest warming at pNEEM associated with this process (i.e., the maximum SAT response to a reduction in GrIS 
volume), the pNEEM site needs to be located in the slope area as depicted in Fig. 9, enhancing the winter mechanism in our model. This corresponds to our EEMr2/EEMr3 experiment, or a scenario where pNEEM is located even closer to the ice sheet margin, suggesting a much smaller GrIS and a much lower altitude of the pNEEM site contrary to the reconstruction by NEEM community members (2013). Clearly, more detailed ice sheet modeling studies and improved reconstructions of the altitude changes at pNEEM are required to solve this contradiction. Moreover, other processes such as a reduced $\mathrm{NH}$ sea ice cover or increased meridional heat transport by ocean currents are needed to fully explain the substantially stronger thermal response observed in the Arctic relative to the $\mathrm{NH}$ lower latitudes during the Eemian interglacial.

Acknowledgements. We kindly thank Vidya Varma and Matthias Prange (University of Bremen) as well as Alex Robinson (Universidad Complutense de Madrid) for providing data used as boundary conditions in the CCSM4 simulations. We also thank Jakob Schwander and two anonymous reviewers for valuable comments. We further acknowledge the Swiss National Supercomputing Centre (CSCS) for providing the supercomputing facilities. This is Past4Future contribution no. 73. The research leading to these results has received funding from the European Union's Seventh Framework Programme (FP7/2007-2013) under grant agreement no. 243908, Past4Future. Climate change - Learning from the past climate. A. Born received financial support by the European Commission under the Marie Curie Intra-European Fellowship ECLIPS (PIEF-GA-2011-300544).

Edited by: V. Rath

\section{References}

Alley, R. B., Andrews, J. T., Brigham-Grette, J., Clarke, G. K. C., Cuffey, K. M., Fitzpatrick, J. J., Funder, S., Marshall, S. J., Miller, G. H., Mitrovica, J. X., Muhs, D. R., Otto-Bliesner, B. L., Polyak, L., and White, J. W. C.: History of the Greenland Ice Sheet: paleoclimatic insights, Quat. Sci. Rev., 29, 1728-1756, 2010.

Bakker, P., Stone, E. J., Charbit, S., Groger, M., Krebs-Kanzow, U., Ritz, S. P., Varma, V., Khon, V., Lunt, D. J., Mikolajewicz, U., Prange, M., Renssen, H., Schneider, B., and Schulz, M.: Last interglacial temperature evolution - a model inter-comparison, Clim. Past, 9, 605-619, doi:10.5194/cp-9-605-2013, 2013.

Berger, A. L.: Long-term Variations of Daily Insolation and Quaternary Climatic Changes, J. Atmos. Sci., 35, 2362-2367, 1978.

Born, A. and Nisancioglu, K. H.: Melting of Northern Greenland during the last interglaciation, Cryosphere, 6, 1239-1250, 2012.

CAPE Last Interglacial Project Members: Last Interglacial Arctic warmth confirms polar amplification of climate change, Quat. Sci. Rev., 25, 1383-1400, 2006.

Colville, E. J., Carlson, A. E., Beard, B. L., Hatfield, R. G., Stoner, J. S., Reyes, A. V., and Ullman, D. J.: Sr-Nd-Pb Isotope Evidence for Ice-Sheet Presence on Southern Greenland During the Last Interglacial, Science, 333, 620-623, 2011.
Cuffey, K. M. and Marshall, S. J.: Substantial contribution to sealevel rise during the last interglacial from the Greenland ice sheet, Nature, 404, 591-594, 2000.

Dansgaard, W., Clausen, H. B., Gundestrup, N., Johnsen, S. J., and Rygner, C.: Dating and climatic interpretation of two deep Greenland ice cores, in: Geophys. Monogr. Ser., 33, 71-76, 1985.

Ettema, J., van den Broeke, M. R., van Meijgaard, E., and van de Berg, W. J.: Climate of the Greenland ice sheet using a highresolution climate model - Part 2: Near-surface climate and energy balance, Cryosphere, 4, 529-544, 2010.

Evans, K. J., Lauritzen, P. H., Mishra, S. K., Neale, R. B., Taylor, M. A., and Tribbia, J. J.: AMIP Simulation with the CAM4 Spectral Element Dynamical Core, J. Climate, 26, 689-709, 2013.

Fischer, N. and Jungclaus, J. H.: Effects of orbital forcing on atmosphere and ocean heat transports in Holocene and Eemian climate simulations with a comprehensive Earth system model, Clim. Past, 6, 155-168, doi:10.5194/cp-6-155-2010, 2010.

Gent, P. R., Danabasoglu, G., Donner, L. J., Holland, M. M., Hunke, E. C., Jayne, S. R., Lawrence, D. M., Neale, R. B., Rasch, P. J., Vertenstein, M., Worley, P. H., Yang, Z. L., and Zhang, M. H.: The Community Climate System Model Version 4, J. Climate, 24, 4973-4991, 2011.

Hakuba, M. Z., Folini, D., Wild, M., and Schar, C.: Impact of Greenland's topographic height on precipitation and snow accumulation in idealized simulations, J. Geophys. Res.-Atmos., 117, D09107, doi:10.1029/2011JD017052, 2012.

Heinemann, G. and Klein, T.: Modelling and observations of the katabatic flow dynamics over Greenland, Tellus A, 54, 542-554, 2002.

Helsen, M. M., van de Berg, W. J., van de Wal, R. S. W., van den Broeke, M. R., and Oerlemans, J.: Coupled regional climate-ice sheet simulation shows limited Greenland ice loss during the Eemian, Clim. Past, 9, 1773-1788, doi:10.5194/cp-9-1773-2013, 2013.

Hobbs, W. H.: The Greenland Glacial Anticyclone, J. Meteorol., 2, 143-153, 1945.

Hoch, S. W., Calanca, P., Philipona, R., and Ohmura, A.: Year-round observation of longwave radiative flux divergence in Greenland, J. Appl. Meteorol. Climatol., 46, 1469-1479, 2007.

Holtslag, A. and Boville, B.: Local versus nonlocal boundary-layer diffusion in a global climate model, J. Climate, 6, 1825-1842, 1993.

Holtslag, A. A. M., Svensson, G., Baas, P., Basu, S., Beare, B., Beljaars, A. C. M., Bosveld, F. C., Cuxart, J., Lindvall, J., Steeneveld, G. J., Tjernstrom, M., and Van de Wiel, B. J. H.: STABLE ATMOSPHERIC BOUNDARY LAYERS AND DIURNAL CYCLES Challenges for Weather and Climate Models, Bull. Am. Meteorol. Soc., 94, 1691-1706, 2013.

Hunke, E. C. and Lipscomb, W. H.: CICE: The Los Alamos Sea Ice Model. Documentation and Software User's Manual. Version 4.0, Los Alamos National Laboratory, Tech. Rep. LA-CC-06012., 76 pp., 2008.

Jouzel, J., Masson-Delmotte, V., Cattani, O., Dreyfus, G., Falourd, S., Hoffmann, G., Minster, B., Nouet, J., Barnola, J. M., Chappellaz, J., Fischer, H., Gallet, J. C., Johnsen, S., Leuenberger, M., Loulergue, L., Luethi, D., Oerter, H., Parrenin, F., Raisbeck, G., Raynaud, D., Schilt, A., Schwander, J., Selmo, E., Souchez, R., Spahni, R., Stauffer, B., Steffensen, J. P., Stenni, B., Stocker, 
T. F., Tison, J. L., Werner, M., and Wolff, E. W.: Orbital and millennial Antarctic climate variability over the past 800,000 years, Science, 317, 793-796, 2007.

Junge, M. M., Blender, R., Fraedrich, K., Gayler, V., Luksch, U., and Lunkeit, F.: A world without Greenland: impacts on the Northern Hemisphere winter circulation in low- and highresolution models, Clim. Dynam., 24, 297-307, 2005.

Kindler, P., Guillevic, M., Baumgartner, M., Schwander, J., Landais, A., and Leuenberger, M.: Temperature reconstruction from 10 to 120 kyr b2k from the NGRIP ice core, Clim. Past, 10, 887-902, doi:10.5194/cp-10-887-2014, 2014.

Kopp, R. E., Simons, F. J., Mitrovica, J. X., Maloof, A. C., and Oppenheimer, M.: Probabilistic assessment of sea level during the last interglacial stage, Nature, 462, 863-U51, 2009.

Kristjansson, J. E. and McInnes, H.: The impact of Greenland on cyclone evolution in the North Atlantic, Quart. J. Roy. Meteorol. Soc., 125, 2819-2834, 1999.

Kristjansson, J. E., Thorsteinsson, S., and Rosting, B.: Phaselocking of a rapidly developing extratropical cyclone by Greenland's orography, Quart. J. Roy. Meteorol. Soc., 135, 1986-1998, 2009.

Lunt, D. J., de Noblet-Ducoudre, N., and Charbit, S.: Effects of a melted greenland ice sheet on climate, vegetation, and the cryosphere, Clim. Dynam., 23, 679-694, 2004.

Merkel, U., Prange, M., and Schulz, M.: ENSO variability and teleconnections during glacial climates, Quat. Sci. Rev., 29, 86-100, 2010.

Merz, N., Raible, C. C., Fischer, H., Varma, V., Prange, M., and Stocker, T. F.: Greenland accumulation and its connection to the large-scale atmospheric circulation in ERA-Interim and paleoclimate simulations, Clim. Past, 9, 2433-2450, doi:10.5194/cp9-2433-2013, 2013.

Neale, R. B., Richter, J. H., Conley, A. J., Park, S., Lauritzen, P. H., Gettelman, A., Rasch, P. J., Vavrus, J., S., Taylor, M. A., C., Zhang, M., and Lin, S.: Description of the NCAR Community Atmosphere Model (CAM4), National Center for Atmospheric Research Tech. Rep. NCAR/TN+STR, 194 pp., 2010.

Neale, R. B., Richter, J., Park, S., Lauritzen, P. H., Vavrus, S. J., Rasch, P. J., and Zhang, M.: The Mean Climate of the Community Atmosphere Model (CAM4) in Forced SST and Fully Coupled Experiments, J. Climate, 26, 5150-5168, doi:10.1175/JCLID-12-00236.1, 2013.

NEEM community members: Eemian interglacial reconstructed from a Greenland folded ice core, Nature, 493, 489-494, doi:10.1038/nature11789, 2013.

Nikolova, I., Yin, Q., Berger, A., Singh, U. K., and Karami, M. P.: The last interglacial (Eemian) climate simulated by LOVECLIM and CCSM3, Clim. Past, 9, 1789-1806, doi:10.5194/cp-9-17892013, 2013.

Oleson, K., Lawrence, D., Bonan, G., Flanner, M., Kluzek, E., Lawrence, P., Levis, S., Swenson, S., Thornton, P., Dai, A., Decker, M., Dickinson, R., Feddema, J., Heald, C., Hoffman, J.F., Mahowald, N., Niu, G.-Y., Qian, T., Randerson, J., Running, S., Sakaguchi, K., Slater, A., Stockli, R., Wang, A., Yang, Z.-L., Zeng, X., and Zeng, X.: Technical Description of version 4.0 of the Community Land Model (CLM), National Center for Atmospheric Research Technical Note NCAR/TN-478+STR, 257 pp., doi:10.5065/D6FB50WZ, 2010.
Otto-Bliesner, B. L., Marsha, S. J., Overpeck, J. T., Miller, G. H., Hu, A. X., and Mem, C. L. I. P.: Simulating arctic climate warmth and icefield retreat in the last interglaciation, Science, 311, 17511753, 2006.

Overpeck, J. T., Otto-Bliesner, B. L., Miller, G. H., Muhs, D. R., Alley, R. B., and Kiehl, J. T.: Paleoclimatic evidence for future ice-sheet instability and rapid sea-level rise, Science, 311, 17471750, 2006.

Petersen, G. N., Kristjansoon, J. E., and Olafsson, H.: Numerical simulations of Greenland's impact on the Northern Hemisphere winter circulation, Tellus A, 56, 102-111, 2004.

Raynaud, D., Chappellaz, J., Ritz, C., and Martinerie, P.: Air content along the Greenland Ice Core Project core: A record of surface climatic parameters and elevation in central Greenland, J. Geophys. Res.-Oc., 102, 26607-26613, 1997.

Robinson, A., Calov, R., and Ganopolski, A.: Greenland ice sheet model parameters constrained using simulations of the Eemian Interglacial, Clim. Past, 7, 381-396, doi:10.5194/cp-7-381-2011, 2011.

Steffen, K. and Box, J.: Surface climatology of the Greenland ice sheet: Greenland climate network 1995-1999, J. Geophys. Res.Atmos., 106, 33951-33964, 2001.

Stone, E. J., Lunt, D. J., Annan, J. D., and Hargreaves, J. C.: Quantification of the Greenland ice sheet contribution to Last Interglacial sea level rise, Clim. Past, 9, 621-639, doi:10.5194/cp-9621-2013, 2013.

Toniazzo, T., Gregory, J. M., and Huybrechts, P.: Climatic impact of a Greenland deglaciation and its possible irreversibility, J. Climate, 17, 21-33, 2004.

van den Broeke, M., van As, D., Reijmer, C., and van De Wal, R.: Sensible heat exchange at the antarctic snow surface: A study with automatic weather stations, Int. J. Climatol., 25, 1081-1101, 2005.

Vizcaino, M., Lipscomb, W. H., Sacks, W. J., van Angelen, J. H., Wouters, B., and van den Broeke, M. R.: Greenland Surface Mass Balance as Simulated by the Community Earth System Model. Part I: Model Evaluation and 1850-2005 Results, J. Climate, 26, 7793-7812, 2013.

Willerslev, E., Cappellini, E., Boomsma, W., Nielsen, R., Hebsgaard, M. B., Brand, T. B., Hofreiter, M., Bunce, M., Poinar, H. N., Dahl-Jensen, D., Johnsen, S., Steffensen, J. P., Bennike, O., Schwenninger, J. L., Nathan, R., Armitage, S., de Hoog, C. J., Alfimov, V., Christl, M., Beer, J., Muscheler, R., Barker, J., Sharp, M., Penkman, K. E. H., Haile, J., Taberlet, P., Gilbert, M. T. P., Casoli, A., Campani, E., and Collins, M. J.: Ancient biomolecules from deep ice cores reveal a forested Southern Greenland, Science, 317, 111-114, 2007.

Yeager, S. G., Shields, C. A., Large, W. G., and Hack, J. J.: The low-resolution CCSM3, J. Climate, 19, 2545-2566, 2006. 